\title{
REVISIÓN DE LA UTILIZACIÓN DE DISTINTOS ÍNDICES ESPECTRALES Y TÉCNICAS PARA LA CARTOGRAFÍA DE ÁREA QUEMADA EN IMÁGENES MODIS
}

\author{
Review of the use of several spectral indices and techniques to \\ map burned area with MODIS images
}

\author{
Patricia Oliva y Felipe Verdú \\ Recibido 26/10/2007; aceptado el 20/01/2008
}

Resumen. En los últimos años se han desarrollado y analizado numerosas técnicas e indices para realizar la cartografía de áreas quemadas a escala regional. En este estudio se realiza la revisión de algunas de estas técnicas sobre la Península Ibérica utilizando imágenes MODIS, poniendo especial énfasis en los índices espectrales y en el análisis IHS (Intensidad, tono, saturación). Además, se aplica una técnica de clasificación supervisada ampliamente utilizada en el análisis de imágenes hiperespectrales, que no ha sido utilizada anteriormente para la cartografía de áreas quemadas, denominada "Spectral Angle Mapper» (SAM). Los mejores valores de separabilidad se han obtenido en el componente tono del análisis IHS, en el SAM y en los indices espectrales que incluyen la banda del SWIR en su formulación. El cálculo de errores y la cartografía generada han demostrado el gran potencial de las técnicas Spectral Angle Mapper e IHS para llevar a cabo la cartografía de área quemada.

Palabras clave: indices espectrales, MODIS, Spectral Angle Mapper, umbrales.

Abstract. In the last decades many techniques and indices have been developed and analysed to accomplish the burned area mapping at regional scale. In this study it has been assessed some of these techniques in the Iberian Peninsula by using MODIS images. It has been stressed the spectral indices and the HIS analysis (Intensity, Hue and Saturation). Besides, it has been applied a supervised classification technique, widely used in hyperspectral images, that has not been used before to map fire-affected area, called "Spectral Angle Mapper" (SAM). Regarding the separability analysis, the higher values have been found in Hue component of IHS technique, SAM and the spectral indexes that included the SWIR band in their computation. Finally, the errors calculation and the final burned area cartography have demonstrated the potential of SAM and IHS to perform the burned area mapping.

Key Words: spectral indices, MODIS, Spectral Angle Mapper, thresholds. 


\section{INTRODUCCIÓN}

La realización de un inventario de áreas afectadas por los incendios forestales es importante a la hora de estimar las pérdidas económicas, evaluar las alteraciones ecológicas, realizar la estimación de las emisiones generadas, cartografiar los cambios de uso del suelo y estimar a corto y largo plazo las consecuencias post-incendio (Koutsias y Karteris, 1998). El uso de la teledetección para la gestión de las zonas quemadas se ha ido desarrollando en las últimas décadas, como se puede comprobar en la abundante literatura disponible que aborda la cartografía de áreas quemadas con la utilización de diferentes sensores y técnicas (Grégoire et al., 2003; Justice et al., 2002a; Koutsias et al., 1999).

La comunidad científica interesada en la química atmosférica, en las emisiones generadas por los incendios y el ciclo del carbono están demandando información sobre la extensión del área quemada y el tiempo que ha estado quemándose la biomasa, a escala global. De hecho, el área y la eficiencia de la combustión de la vegetación quemada mensual o anualmente es uno de los parámetros que proporciona mayor incertidumbre en el cálculo de las emisiones de gases y aerosoles y en la estimación de la biomasa quemada.

Bajo estas necesidades, en el presente estudio se lleva a cabo la cartografía de área quemada con imágenes de satélite de resolución media/baja y se realiza una propuesta de metodología a seguir para realizar la cartografía de áreas quemadas.

\section{Antecedentes y situación actual}

A escala global la mayoría de los estudios sobre cartografía de área quemada han sido realizados utilizando imágenes NOAA-AVHRR (Advanced Very High Resolution Radiometer), ERS y ATSR (Along-Track Scanning Radiometer). Sin embargo, la llegada de una nueva generación de sensores diseñados para estudios medio ambientales, como el MODIS (Moderate Resolution Imaging Spectroradiometer) y el Envisat-MERIS (Medium Resolution Imaging Spectrometer) pueden ofrecer importantes avances en la cartografía de áreas quemadas, al mejorar la resolución espectral y espacial de las imágenes NOAA-AVHRR (Martín et al.,, 2002). Los métodos derivados de las investigaciones realizadas con los primeros sensores pueden adaptarse y ser utilizados para llevar a cabo el tratamiento de las imágenes procedentes de los nuevos sensores.

En el trabajo realizado por Chuvieco et al. (2002) se llevó a cabo la comparación de la cartografía de área quemada obtenida a través de imágenes NOAA-AVHRR e imágenes MODIS. Llegando a la conclusión de que los datos MODIS son más apropiados para la realización de la cartografía de área quemada debido a su mejor resolución espacial y espectral.
La caracterización y detección de áreas quemadas ha sido estudiada en varias regiones del espectro (Pereira et al., 1999). Después de dichos estudios se concluye que el infrarrojo cercano es la región del espectro donde la discriminación de los incendios recientes es más nítida, y es generalmente considerada como la mejor banda espectral para la detección y delimitación del área quemada, (Pereira y Setzer, 1993); (Pereira et al., 1999b). El rango visible del espectro no resulta adecuado para la discriminación de áreas quemadas debido a la posible confusión con otras coberturas que dan la misma respuesta espectral (Pereira et al.,n 1999b). El MIR (infrarrojo medio), presenta, en general, mayor capacidad para identificar áreas quemadas que el visible y es mucho menos sensible a alteraciones atmosféricas (López García y Caselles, 1991).

Se han utilizado una gran variedad de técnicas para llevar a cabo la cartografía de áreas quemadas, desde las más simples como el análisis visual, a las más complejas como el análisis de mezclas espectrales o las redes neuronales. La metodología utilizada en la evaluación de las áreas quemadas dependerá de la resolución temporal, espacial y espectral de las imágenes disponibles (Vázquez et al., 2001).

\section{Índices Espectrales}

Los índices espectrales de vegetación han sido unas herramientas muy utilizadas en la cartografía de áreas quemadas, tanto para el análisis unitemporal como para el multitemporal. Cuando examinamos la firma espectral de la vegetación, la pendiente observada entre el rojo y el infrarrojo constituye una variable sensible al estado de la vegetación. Los indices de vegetación tienen en cuenta el contraste espectral entre estas dos bandas para mejorar la señal de la vegetación mientras se minimizan los efectos atmosféricos, de irradiancia solar y del suelo (Chuvieco, 2002). Se ha demostrado que estos índices de vegetación pueden ser utilizados para la discriminación de áreas quemadas obteniendo buenas precisiones. Varios estudios han puesto de manifiesto como las plantas quemadas tienden a presentar una mayor reflectividad que las plantas vivas en el rango del visible, mientras que presenta una reflectividad más baja en el infrarrojo cercano (Pereira et al.,, 1999b). Pero esta respuesta espectral origina una gran confusión con el agua, las zonas con sombra, y zonas urbanas, principalmente.

Realizando una revisión de algunos de los índices de vegetación utilizados, basados en el contraste entre las bandas del rojo y el infrarrojo, encontramos los siguientes índices:

- El Índice de Vegetación de Diferencia Normalizada (NDVI, Normalize Difference Vegetation Index), que ha sido ampliamente utilizado para la discriminación de zonas quemadas pero en los últimos años se ha ido demostrando su peor ajuste frente a otros índices, 
en el ecosistema mediterráneo (Chuvieco et al.," 2002b; Pereira et al.,, 1997). Aunque se sigue utilizando actualmente ya que si funciona en los bosques boreales.

$$
N D V I=\frac{\left(\rho_{N I R}-\rho_{R E D}\right)}{\left(\rho_{N I R}+\rho_{R E D}\right)}
$$

- El Índice SAVI (Soil Adjusted Vegetation Index), el cual ha resultado ser sensible a la discriminación de la vegetación en zonas de vegetación dispersa. Huete (1998) mostró que un valor de $L=0,5$ permite un mejor ajuste.

$$
S A V I=\frac{\left(\rho_{N I R}-\rho_{R E D}\right)}{\left(\rho_{N I R}-\rho_{R E D}+L\right)} \times(1+L)
$$

Donde el término L tiene en cuenta la diferencia en la transmisividad de la cubierta en el rojo y en el infrarrojo cercano. Se ha demostrado que el valor de 0,5 proporciona buenos resultados para una gran variedad de condiciones (Huete, 1988), y $(1+\mathrm{L})$ es un factor que mantiene los valores de este índice en el mismo rango que el NDVI.

- GESAVI (Generalizad Soil-Adjusted Vegetation Index), se define en base a dos parámetros, $A$ y $B$, que caracterizan al suelo (Martínez et al., 2002).

$$
G E S A V I=\frac{\rho_{N I R}-B \cdot \rho_{R E D}-A}{R+Z}
$$

Donde $Z$ se define como el coeficiente de ajuste del suelo. La línea de suelo establecida por los parámetros $A$ y $B$, y el coeficiente $Z$ tienen que ser determinados dependiendo de las propiedades específicas de la imagen con el fin de calcular correctamente este índice. La elección del coeficiente $Z$ es crucial en el cálculo del índice. Por lo tanto, se requiere un conocimiento previo de la zona. Sin embargo, la información relativa a la vegetación puede no estar disponible. Este es una inconveniente importante que ha hecho que este índice no haya sido muy utilizado.

- GEMI (Global Environmental Monitoring Index), se creó como alternativa del NDVI ya que está menos afectado por el suelo y las condiciones atmosféricas (Pinty y Verstraete, 1992). Se ha probado también que es más apropiado para la cartografía de áreas quemadas que el NDVI (Martín y Chuvieco, 1998).

$$
G E M I=\eta(1-0.25 \eta)-\left[\frac{\rho_{R E D}-0.125}{1-\rho_{R E D}}\right]
$$

$$
\eta=\frac{\left|2 \cdot\left(\rho_{N I R}^{2}-\rho_{R E D}^{2}\right)+1.5 \rho_{R E D}\right|}{\rho_{N I R}+\rho_{R E D}+0.5}
$$

- El Índice de Área Quemada (IAO) o Burn Area Index (BAI) definido por (Martín, 1998) específicamente para la discriminación de áreas quemadas. Este indice se basa en la distancia establecida entre cada píxel y un valor espectral de referencia, al cual las áreas recientemente quemadas tienden a converger:

$$
B A I=\frac{1}{\left(p c_{R E D}-\rho_{R E D}\right)^{2}+\left(p c_{N I R}-\rho_{N I R}\right)^{2}}
$$

Donde $p c_{\text {RED }}$ Y $p c_{\text {NIR }}$ son las reflectividades de referencias en el rojo y en el infrarrojo cercano, respectivamente, $y \rho_{\text {RED }}$ Y $\rho_{\text {NIR }}$ son las reflectividades de cada pixel en dichas bandas. Los valores de los puntos de convergencia se definieron para imágenes AVHRR como 0,1 y 0,06 para el rojo e infrarrojo cercano, respectivamente, basándose en la literatura y en el análisis de varios grupos de imágenes de satélite. Estos valores tienden a enfatizar la señal del carbón de las áreas quemadas.

Por otro lado, otros estudios han demostrado el potencial de las bandas del SWIR para la cartografía de áreas quemadas (Martín et al., 2002, Pereira et al.,, 1999b, Rogan y Franklin, 2001). Los resultados obtenidos pusieron de manifiesto que con los índices compuestos en parte o únicamente por la banda del SWIR se obtuvieron las mayores precisiones en las clasificaciones realizadas. El contenido de agua de las plantas, representado por la banda del SWIR, se confirmó como un parámetro clave a la hora del seguimiento de variaciones en el estado de la vegetación a través de imágenes de satélite (Key y Benson, 2005). A partir de la nueva generación de satélites en los cuales se incluyen bandas en el SWIR, se produjo la generación de nuevos índices destinados a la delimitación de áreas quemadas. A continuación se comentan los índices más utilizados:

- Normalized Difference Infrared Index (NDII) también denominado Normalized Burn Ratio (NBR). El índice NDIl fue desarrollado en primer lugar por Hunt y Rock (1989), un índice análogo el Sort Wave Vegetation Index (SWVI) fue aplicado por Fraser et al. (2000) a datos SPOT-VEGETATION, y en imágenes Landsat-TM por (López García y Caselles, 1991), basándose en las bandas 4 y 7 del Landsat. Key y Benson (2005) denominaron este índice como Normalized Burn Ratio:

$$
N B R=\frac{(\rho 4-\rho 7)}{(\rho 4+\rho 7)}
$$


Este índice ha sido utilizado por varios autores en el campo de la cartografía de áreas quemadas y para el estudio de la severidad del incendio. (Garcia y Chuvieco, 2004) calcularon el NBR para imágenes SAC$C / M M R S$ para cartografiar grandes incendios en España. Concluyeron que la utilización de este índice aclaraba la confusión que se establece entre las áreas quemadas y, las láminas de agua y las sombras de nubes.

- BAIM (Burn Area Index MODIS). El BAI anteriormente descrito ha sido modificado con la inclusión de una banda deI SWIR $(1,3-2 \mu \mathrm{m})$, la cual se ha demostrado que es sensible a la discriminación de las áreas quemadas (Chuvieco et al.,, 2002b, López García and Caselles 1991, Fraser et al.,, 2000). Este nuevo índice se ha desarrollado para imágenes MODIS por Martín (2005), utilizando el infrarrojo cercano y el SWIR (bandas 2 y 7 a 500 metros de resolución), las cuales se han mostrado como las mejores bandas para la discriminación de áreas quemadas (Koutsias y Karteris, 2000; Martín et al.,, 2005; Pereira, 1999)

$$
B A I M=\frac{1}{\left(p c_{N I R}-\rho_{N I R}\right)^{2}+\left(p c_{S W I R}-\rho_{S W I R}\right)^{2}}
$$

Donde $p c_{N I R}$ y $p c_{S W I R}$ son las reflectividades de referencias en el rojo y en el infrarrojo cercano, respectivamente, Y NIR Y sWIR son las reflectividades de cada píxel en dichas bandas. Los valores de los puntos de convergencia se definieron como 0,05 y 0,2 para el infrarrojo cercano y para el SWIR, respectivamente.

\section{Intensidad, Tono, Saturación (IHS)}

En general, este método transforma los valores de una composición de tres canales de forma que la información espacial se separa en el componente de intensidad, mientras que la información espectral se separa en los componentes de tono y saturación (Koutsias et al.,, 2000). El componente de tono de dos composiciones RGB de los canales TM7, TM4 y TM1, ha probado ser muy útil en la cartografía de áreas quemadas. Se ha demostrado que la transformación IHS puede resultar muy práctica al no necesitar correcciones radiométricas, ni la definición de áreas de entrenamiento, y se reducen considerablemente las confusiones entre las áreas quemadas y otras cubiertas, como sombras, áreas urbanas y láminas de agua. Su inconveniente está relacionado con el ámbito de aplicación, ya que ha demostrado ser una técnica útil a escala local, sin embargo no se ha comprobado su aplicación en la cartografía de áreas quemadas a escala regional.

\section{Umbrales Múltiples}

Los umbrales múltiples pueden incluirse en un amplio grupo de clasificadores de árbol o sistemas expertos. Se basan en el establecimiento de reglas consecutivas o paralelas que implican la aceptación o rechazo de un píxel determinado. Estos sistemas han sido muy utilizados para la discriminación de "hot-spots» en la detección de incendios activos. Para la cartografía de áreas quemadas son menos comunes, pero hace unos años se desarrollaron algunas aplicaciones que ponen de manifiesto su gran potencial. Pereira et al. (1999) y Martín (1998) utilizaron este sistema para la cartografía de áreas quemadas de grandes incendios en el área Mediterránea con imágenes AVHRR. Esta técnica presenta como ventaja la posibilidad de utilizar varias bandas combinándolas, para mejorar la discriminación de las áreas quemadas. Los umbrales múltiples en imágenes de una sola fecha (Martín, 1998; Pereira et al.,, 1999a) han sido ampliamente utilizados y desarrollados obteniendo buenos resultados.

El inconveniente de esta técnica reside en el establecimiento de los umbrales, ya que estos dependen del área de estudio y de la fecha de adquisición de la imagen. Lo ideal sería que los valores de los umbrales establecidos fueran validos no sólo para la imagen que se está estudiando, y que fueran útiles para otras áreas de estudio y periodos (Garcia y Chuvieco, 2004).

Por otro lado, varias coberturas ofrecen una gran confusión con las áreas quemadas, como las láminas de agua, las sombras, las áreas urbanas, el suelo desnudo, las afloraciones rocosas y los píxeles con mezcla de tierra y agua (Barbosa et al.,, 2002). Estas posibles confusiones varian con el tipo de ecosistema, el tiempo transcurrido entre la adquisición de la imagen y la ocurrencia del incendio y los métodos de clasificación de los datos.

Los métodos multitemporales parecen ser más ventajosos, ya que el fuego es un agente que produce la alteración de las coberturas, de manera que los métodos de detección de cambios ayudan a reducir la confusión con las coberturas que no cambian en un periodo de tiempo no muy largo, como las áreas urbanas, las láminas de agua y afloramientos rocosos (Chuvieco et al.,, 2002a).

\section{Clasificación supervisada y no supervisada}

La clasificación de las imágenes de satélite implica una serie de procedimientos diseñados para categorizar todos los píxeles de una imagen automáticamente en distintas clases de coberturas. Los canales del Landsat TM han sido muy utilizados, debido a que su alta resolución espectral es la apropiada para realizar clasificaciones multiespectrales, mientras su alta resolución espacial facilita la selección de áreas de entrenamiento (Pereira et al., 1999). 
La clasificación a partir del Ángulo Espectral es una técnica de clasificación supervisada muy utilizada en análisis de imágenes hiperespectrales, ya que permite trabajar con todas las bandas de la imagen (Debba et al.,, 2005). Su funcionamiento se basa en la creación de un vector con todas las bandas correspondiente a cada una de las clases establecidas en las áreas de entrenamiento. A continuación se compara dicho ángulo con el de cada píxel de la imagen calculando el denominado "ángulo espectral» para cada uno de los espectros de referencia. Los píxeles de la imagen se asignan a aquella categoría en la que el ángulo espectral sea menor. Esta técnica no se ha utilizado hasta el momento para delimitación de áreas quemadas o no se tiene constancia de ello, pero puede tener un gran potencial, dado que se pueden incluir como bandas índices de vegetación o componentes creados a partir de uno de los métodos anteriormente descritos.

\section{OBJETIVO}

El objetivo principal de este trabajo es la generación de la cartografía de áreas quemadas en España en el periodo entre Junio y Agosto de 2001, explorando el potencial de ciertas técnicas para realizar la cartografía de áreas quemadas.

\section{METODOLOGÍA}

\section{Zona de Estudio}

Este estudio se centra en la península lbérica e islas Baleares, aunque en el producto final se incluirá solo España y las islas (excepto el archipiélago canario). Se han obtenido imágenes MODIS en un compuesto de 8 dias, y se han elegido dos fechas, una al principio de la temporada de incendios (junio) y otra al final (agosto). De esta forma podremos establecer las áreas quemadas para el periodo de máxima ocurrencia de incendios.

De manera que se realizará un estudio a escala regional lo cual implica una gran variedad de condiciones ambientales, sobre todo tratándose de España, ya que presenta una gran proporción de costa y de cordillera montañosa frente a otros paises. Por lo tanto, aparece una variabilidad importante de las cubiertas que debe ser tenida en cuenta tanto para la elección de la metodología como en la interpretación de los resultados obtenidos.

\section{Imágenes de satélite utilizadas}

El sensor MODIS (Moderate Resolution Imaging Spectroradiometer) está embarcado en dos satélites el TERRA y el AQUA. Ambos son satélites de órbita polar que pasan por el Ecuador por la mañana (TERRA, 10:30) y a media tarde (AQUA, 14:30). El sensor MODIS tiene 36 canales, 2 con una resolución espacial de 250 metros, cinco con una resolución de 500 metros y el resto con una resolución de 1 kilómetro, que se sitúan entre unas longitudes de onda de $0.4 \mu \mathrm{m}$ hasta $14.4 \mu \mathrm{m}$. Posee una resolución temporal de 1-2 días según las latitudes. Un resumen de los productos de MODIS se puede encontrar en (Justice et al.,, 1998; Justice et al.,, 2002b). Está previsto que en breve se ofrezca entre los productos MODIS uno sobre área quemada diseñado por Roy et al., (2005a).

Para este proyecto se han utilizado las imágenes del producto MOD09A1, que es un compuesto de reflectividad de 8 dias que incluye las bandas de mayor resolución de MODIS: 1, 2, 3, 4, 5, 6 y 7 (centradas a $648 \mathrm{~nm}, 858 \mathrm{~nm}, 470 \mathrm{~nm}, 555$ $\mathrm{nm}, 1240 \mathrm{~nm}, 1640 \mathrm{~nm}$, y $2130 \mathrm{~nm}$, respectivamente). Este producto ofrece las 7 bandas con un factor de escalado de 10000, lo cual hay que tener en cuenta a la hora del cálculo de algunos índices.

Este sensor está siendo muy utilizado para diversos estudios. En el ámbito de los incendios forestales se ha utilizado tanto para la cartografía de áreas quemadas (Chuvieco et al., 2002b; Li et al., 2004b; Martín et al., 2002; Roy et al., 1999) como para el cálculo del contenido de humedad de combustible vivo (Dennison et al., 2005) o la detección de incendios activos (Giglio et al., 2003), entre otros.

Las imágenes MODIS se han obtenido a partir del servicio que ofrece EOS Data Gateway (Fuente: http://redhook. gsfc.nasa.gov/ imswww/pub/imswelcome/). En primer lugar se procedió a la creación de los mosaicos correspondientes a las fechas seleccionadas, reproyectados a UTM $30 T 1950$ y recortados a fin de trabajar únicamente con la zona correspondiente a la península Ibérica. Esta primera fase se realizó para todos aquellos compuestos de 8 días disponibles entre el 25 de mayo y el 5 de septiembre. Posteriormente se realizó una exploración visual de las imágenes obtenidas, eligiéndose finalmente los compuestos comprendidos entre el 2 y el 9 de junio y el 21 y 28 de agosto, ya que se consideró que entre estas fechas se localizaban la mayoría de los incendios ocurridos en la temporada de incendios de 2001.

Para eliminar los errores potenciales localizados en las zonas costeras se aplicó una máscara obtenida a partir de una imagen vectorial que comprendía el perímetro de la Península y Baleares. Al mismo tiempo, se utilizó el CORINE Land Cover 2000 para la creación de máscaras de láminas de agua y suelo urbano.

Para realizar la validación de los resultados se ha utilizado una imagen Landsat-ETM localizada entre España y Portugal, localizada en la región donde se encuentra la mayor densidad de incendios ocurridos en la Península para el año 2001.

\section{Índices espectrales}

En este estudio se han utilizado los siguientes indices espectrales con el fin de probar su sensibilidad en la carto- 
grafía de áreas quemadas. El NDVI (1) fue diseñado para la cartografía de vegetación vigorosa de manera que su utilidad para la discriminación de áreas quemadas ha sido muy cuestionada. A raíz de los inconvenientes que presenta el NDVI se fueron desarrollando índices que pretendian reducir dichos inconvenientes. Uno de ellos es el SAVI (2) que se diseñó para reducir el efecto del suelo que sufre el NDVI, pero este índice no es de los más eficaces en la cartografía de áreas quemadas. Posteriormente el GEMI (3) (Pinty y Verstraete, 1992), es un índice no lineal diseñado para disminuir los efectos de la atmósfera y del suelo de la señal recibida. Este índice ha sido utilizado con resultados satisfactorios en la cartografía de áreas quemadas (Pereira, 1999).

De manera que, en este estudio se eligió el índice GEMI y se calculó también el NDVI para verificar los resultados ofrecidos anteriormente por Martín y Chuvieco (1998) y Pereira (1999). También se calcularon los siguientes índices: NBR y BAI MODIS, cuyo potencial se ha explicado anteriormente. Estos dos últimos índices han sido utilizados en varios estudios con muy buenos resultados (Garcia y Chuvieco, 2004; Martín et al.,, 2005).

Por otro lado, a parte de los índices espectrales se ha realizado el cálculo de los componentes IHS (Intensity, Hue, Saturation) a partir de la composición RGB de las bandas 7, 2 y 1 de MODIS. Como se ha descrito anteriormente el componente de tono (Hue) ha demostrado ser muy útil para la cartografía de áreas quemadas a escala local, por lo que en este estudio se quiere comprobar su utilidad a escala regional.

Por último también se ha realizado una clasificación supervisada a través de la técnica de Medida del Ángulo espectral (Spectral Angle Mapper, SAM), con el fin de explorar el potencial de esta técnica para la cartografía de áreas quemadas. Esta técnica reduce toda la información contenida en la imagen, que puede incluir todas las capas de información que se crean necesarias, en un vector en el cual el módulo del vector es el albedo, y la dirección del vector se define por la forma del continuo. Este método discrimina los pixeles de la imagen en función de la firma espectral que presente una determinada cubierta y no tiene en cuenta el albedo, de manera que es capaz de recoger la variabilidad que ofrecen las áreas quemadas. Se desconoce si este método ha sido utilizado anteriormente para la discriminación de áreas quemadas, pero desde nuestro punto de vista puede ser una técnica más efectiva que la clasificación supervisada convencional. En este estudio se han utilizado únicamente las bandas de la imagen para el cálculo de la imagen de ángulos espectrales correspondiente a la firma espectral de quemado. Para dicha firma espectral de referencia de área quemada se consideró el espectro medio de una muestra aleatoria de puntos situados dentro de los perímetros de validación.

\section{Separabilidad}

La medida utilizada para cuantificar la efectividad con la cual cada banda espectral, índice o técnica separa las áreas quemadas de las demás cubiertas, ha sido la diferencia normalizada, que se define como(Pereira, 1999):

$$
M=\frac{\left|\left(\mu_{c}-\mu_{q}\right)\right|}{\left(\sigma_{c}+\sigma_{q}\right)}
$$

Donde: $\mu_{c}$ es la media de cada una de las cubiertas no quemadas, $\mu_{\mathrm{q}}$ es la media de las áreas quemadas, $\sigma_{\mathrm{c}}$ es la desviación estándar de los valores de cada una de las cubiertas de no quemado y $\sigma_{q}$ es la desviación estándar de los valores de las áreas quemadas.

Los valores de M mayores de 1 indican una buena separabilidad, mientras que los valores menores de 1 representan una importante superposición de los histogramas de las dos clases de las que se trate.

A partir de esta medida se ha procedido a elegir las bandas espectrales más adecuadas para la discriminación de las áreas quemadas, así como que índice espectral o técnica utilizada ofrece una mejor separabilidad y, con ello, elegir aquellos que mejores resultados ofrezcan.

\section{Técnicas utilizadas para la cartografía de áreas quemadas}

Una vez calculados los índices espectrales y aplicadas las técnicas de clasificación y realce elegidas en este estudio, se procedió a realizar la cartografía de las áreas quemadas en España. Este proceso se llevó a cabo en dos fases. El objetivo de la primera fase consiste en minimizar los errores de comisión. Para ello se persigue obtener píxeles denominados "semilla", que serán los píxeles más severamente afectados por el incendio, y que se utilizarán en la siguiente fase para delimitar el área del incendio correspondiente. Para obtener estos píxeles el paso más importante fue establecer los umbrales, de tal manera que la mayor parte de los incendios estuvieran representados por al menos 3 píxeles. A partir de ellos se obtuvo una imagen clasificada en quemado y no quemado. Los umbrales elegidos varian dependiendo del índice o técnica de que se trate, ya que se calculan a partir de la media y la desviación típica obtenidas a través de la muestra de puntos aleatorios situados en el interior de los perímetros de validación.

En la segunda fase estos píxeles identificados como quemado se utilizan como semilla en un algoritmo de contexto. A partir de este algoritmo se incluyen como quemado píxeles contiguos a las semillas a través de criterios espectrales y espaciales. De tal manera que se incluyen como incendios aquellos píxeles en un radio de dos kilómetros de los píxeles semilla siempre que cumplieran la condición de semejanza 
espectral establecida en cada caso. Así, el crecimiento espacial de las semillas terminará cuando se cumplan los criterios de homogeneidad establecidos (Garcia y Chuvieco, 2004). Este algoritmo también es específico de cada índice y técnica ya que depende de la media y la desviación típica. El objetivo de esta segunda fase es, por lo tanto, minimizar los errores de omisión incluyendo como quemado también los píxeles menos afectados por el incendio.

De manera que, este método permite mejorar la delimitación del área afectada por los incendios comenzando por la identificación de los píxeles más quemados. La razón por la cual la cartografía de áreas quemadas se realiza en dos fases está relacionada con la gran variabilidad de respuesta espectral que presentan las áreas quemadas (Garcia y Chuvieco, 2004). Las principales fuentes de variabilidad se relacionan con el tipo de especie afectada, los grados de severidad presentes en un incendio y el tiempo transcurrido entre el incendio y la adquisición de la imagen (Pereira, 1999). Cuando sólo se aplican umbrales aparecen tanto errores de omisión como de comisión debido a la variabilidad de las áreas quemadas. Sin embargo, al aplicar este método en dos fases, se elimina el efecto ocasionado por los diferentes niveles de severidad, ya que la primera fase se centra en detectar los píxeles más quemados, mientras que en la segunda fase se incorporan aquellos cuya severidad es menor.

Por ello, el factor más importante en este método es la elección de los umbrales que discriminan los píxeles com- pletamente quemados, de forma que se encuentre una buena relación entre los errores de omisión y comisión que se obtienen al aplicar esta metodología.

\section{Validación}

La cartografía resultante se validó con los polígonos digitalizados a través de la interpretación visual de una composición $\operatorname{RGB}(7,4,1)$ de una imagen Landsat-ETM situada entre la Península Ibérica y Portugal. El análisis de validación de la cartografía se realizó a partir del cálculo de la matriz de confusión, tomando como referencia los polígonos digitalizados. De manera que, se obtuvieron los errores de omisión y comisión para cada una de las técnicas utilizadas.

\section{RESULTADOS}

\section{Separabilidad}

En la tabla que se adjunta a continuación se puede apreciar los valores de la separabilidad, M. Como se ha indicado anteriormente, valores por encima de 1 indican una mejor separabilidad, esto significa que se discriminan mejor las áreas quemadas con respecto a las distintas cubiertas.

En este caso, las bandas 2 y 5 presentan una separabilidad superior a 1 para todas las cubiertas; y las bandas 1, 3 y 7 tienen separabilidades superiores a 1, excepto para una cu-

FIGURA 1. Separabilidad espectral.

\begin{tabular}{|c|c|c|c|c|c|c|}
\hline Separabilidad $^{1}$ & SDesnudo & CS & AGUA & VEGETACIÓN & CR & Media \\
\hline Banda 1 & 2,48 & 3,35 & 1,15 & 1,15 & 0,77 & 1,78 \\
\hline Banda 2 & 3,69 & 3,87 & 1,32 & 3,10 & 3,97 & 3,19 \\
\hline Banda 3 & 0,94 & 2,75 & 1,45 & 1,64 & 1,25 & 1,61 \\
\hline Banda 4 & 1,71 & 3,18 & 0,57 & 0,38 & 0,04 & 1,18 \\
\hline Banda 5 & 2,43 & 3,22 & 1,58 & 1,88 & 2,12 & 2,25 \\
\hline Banda 6 & 1,30 & 2,68 & 1,79 & 0,35 & 0,28 & 1,28 \\
\hline Banda 7 & 0,48 & 1,96 & 2,36 & 2,20 & 1,74 & 1,75 \\
\hline BAIM - Agosto & 0,70 & 0,70 & 0,25 & 0,69 & 0,70 & 0,61 \\
\hline NBR - Agosto & 2,44 & 2,11 & 0,96 & 5,04 & 4,31 & 2,97 \\
\hline NDVI - Agosto & 0,29 & 0,51 & 0,13 & 5,36 & 3,87 & 2,03 \\
\hline GEMI - Agosto & 0,22 & 0,28 & 1,67 & 4,46 & 4,24 & 2,17 \\
\hline Resta BAIM ${ }^{3}$ & 0,67 & 0,67 & 0,00 & 0,67 & 0,68 & 0,54 \\
\hline Resta NBR & 1,52 & 2,25 & 0,75 & 2,11 & 2,46 & 1,82 \\
\hline Resta NDVI & 0,11 & 1,35 & 0,01 & 1,87 & 2,07 & 1,08 \\
\hline Resta GEMI & 0,11 & 1,03 & 1,93 & 1,65 & 2,17 & 1,38 \\
\hline SAM & 1,89 & 2,49 & 1,76 & 5,51 & 4,51 & 3,23 \\
\hline HUE - Agosto & 2,87 & 2,09 & 0,97 & 6,48 & 5,66 & 3,61 \\
\hline
\end{tabular}

1 En azul se han marcados los valores por encima de 1.

$221-28$ agosto.

3 Resta = Agosto-Junio. 
bierta de las 5 consideradas. La banda 5 del sensor MODIS presenta un problema de bandeado reconocido, de manera que no se tiene en cuenta para el cálculo de los índices espectrales. Los valores medios más altos para cada una de las bandas se encuentran en las bandas 1, 2 y 7, utilizadas en el cálculo de los índices. En el caso de los índices espectrales, los valores medios más altos se localizan en el NBR-Agosto, SAM, GEMI-Agosto y la componente HUE del IHS de Agosto.

En cuanto a los índices espectrales si atendemos a la imagen post-incendio, el que ofrece un mejor resultado es el NBR $(2,97)$, seguido por el GEMI $(2,17)$. El índice que presenta peores valores de separabilidad ha sido el BAIM, de forma contraria a lo esperado tras la discriminación visual de los incendios. Esta situación se debe a la gran variabilidad de los valores que presenta el BAIM para áreas quemadas, lo cual origina que tenga una gran desviación típica, disminuyendo así el valor de separabilidad. El NDVI de la imagen post-incendio confunde suelo, agua y cultivo de secano, mientras que diferencia muy bien vegetación y cultivo de regadío. Encontramos la misma situación en los resultados de separabilidad al observar el análisis multitemporal, excepto para el NDVI, que en este caso también presenta un valor superior a 1 para cultivos de secano.

El componente tono del IHS de la imagen post-incendio y el componente de incendios de la clasificación por ángulo espectral (SAM), presentan los mayores valores de separabilidad, respecto a los índices espectrales. Entre ellos el que presenta mayores valores, en general, es el componente Tono de la imagen post-incendio, sin embargo el SAM es el único que presenta separabilidades superiores a 1 para todas las cubiertas. Esto se corresponde con lo observado de forma visual ya que se distinguen nítidamente y no muestran confusión con las láminas de agua.

De manera que se optó por realizar el procedimiento desarrollado anteriormente, a la imagen post-incendio del NBR, del BAIM, al componente Tono y al SAM. Se eligió utilizar el BAIM porque los datos de separabilidad obtenidos no se corresponden con lo observado visualmente y porque según los estudios previos ha sido un índice que ha mostrado buenos resultados (Martín et al., 2002; Martín et al., 2005).

\section{Umbrales y algoritmo de contexto}

En primer lugar se presentan en la siguiente tabla los umbrales escogidos para la discriminación de los píxeles severamente afectados por el fuego, para cada una de las técnicas empleadas.

En el siguiente paso se aplicó el algoritmo de contexto considerando, por un lado, los píxeles debían encontrarse dentro de un radio de dos kilómetros a partir de cada píxel considerado como "semilla». Y, por otro lado, se estableció el criterio de similitud espectral considerando un umbral me
Figura 2. Umbrales de detección y de contexto.

\begin{tabular}{ccc}
\hline & Umbral 10 fase & Umbral 2 ${ }^{\circ}$ fase \\
NBR & media + 1,5 DT & media + 2,2DT \\
BAIM & media + 1,2 DT & media + 0,9DT \\
IHS & Media $<$ HUE $<250$ & Media-1DT $<$ HUE $<250$ \\
SAM & 0,05 & 0,1 \\
\hline
\end{tabular}

nos rígido que el utilizado para la determinación de las semillas. De manera que, los píxeles afectados menos severamente fueran incluyéndose dentro del área quemada. Los nuevos umbrales utilizados se presentan en la tabla anterior.

Los umbrales establecidos para el SAM no tienen en cuenta la media y la desviación típica, ya que al realizar la clasificación se establece que son aquellos píxeles con una distancia espectral menor de 0,1 grados los que se incluyen como quemado. De manera que se estableció el valor de 0,05 para hallar los píxeles más quemados y posteriormente 0,1 para incluir los píxeles vecinos como área quemada.

\section{Validación}

Las áreas quemadas que se obtuvieron visualmente a partir de la imagen LANDSAT fueron 73, con un rango amplio del tamaño de los mismos, desde 3ha hasta más de 6000ha. Esto repercutirá en el cálculo de los errores de omisión y comisión, dado que se han incluido áreas muy pequeñas que debido a la resolución espacial de MODIS, no serán detectadas.

En la Figura 4 se puede observar la cartografía de área quemada obtenida como resultado final de la aplicación de la metodología descrita anteriormente.

Los errores de omisión y comisión que los distintos índices y métodos empleados en este trabajo se presentan en la siguiente tabla:

FiguRa 3. Error Omisión y Comisión.

$\begin{array}{ccc} & \text { Omisión } & \text { Comisión } \\ \text { BAIM } & 53,8 \% & 18,5 \% \\ \text { HUE } & 44 \% & 20 \% \\ \text { NBR } & 77,7 \% & 7,8 \% \\ \text { SAM } & 52,8 \% & 15,4 \%\end{array}$

El BAIM presenta el error de omisión más alto con un valor del 60\%, mientras que para el error de comisión es el que menor error presenta de los cuatro indices utilizados (32\%). El índice utilizado que menor error de omisión presenta es el proveniente del SAM, con un valor entorno al $33 \%$, seguido del HUE con un valor del 44\%. En cambio, los errores de comisión de estos dos índices son muy próximos. El NBR presenta el valor más elevado para el error de omi- 
FigurA 4. Cartografía final de área quemada en el año 2001.

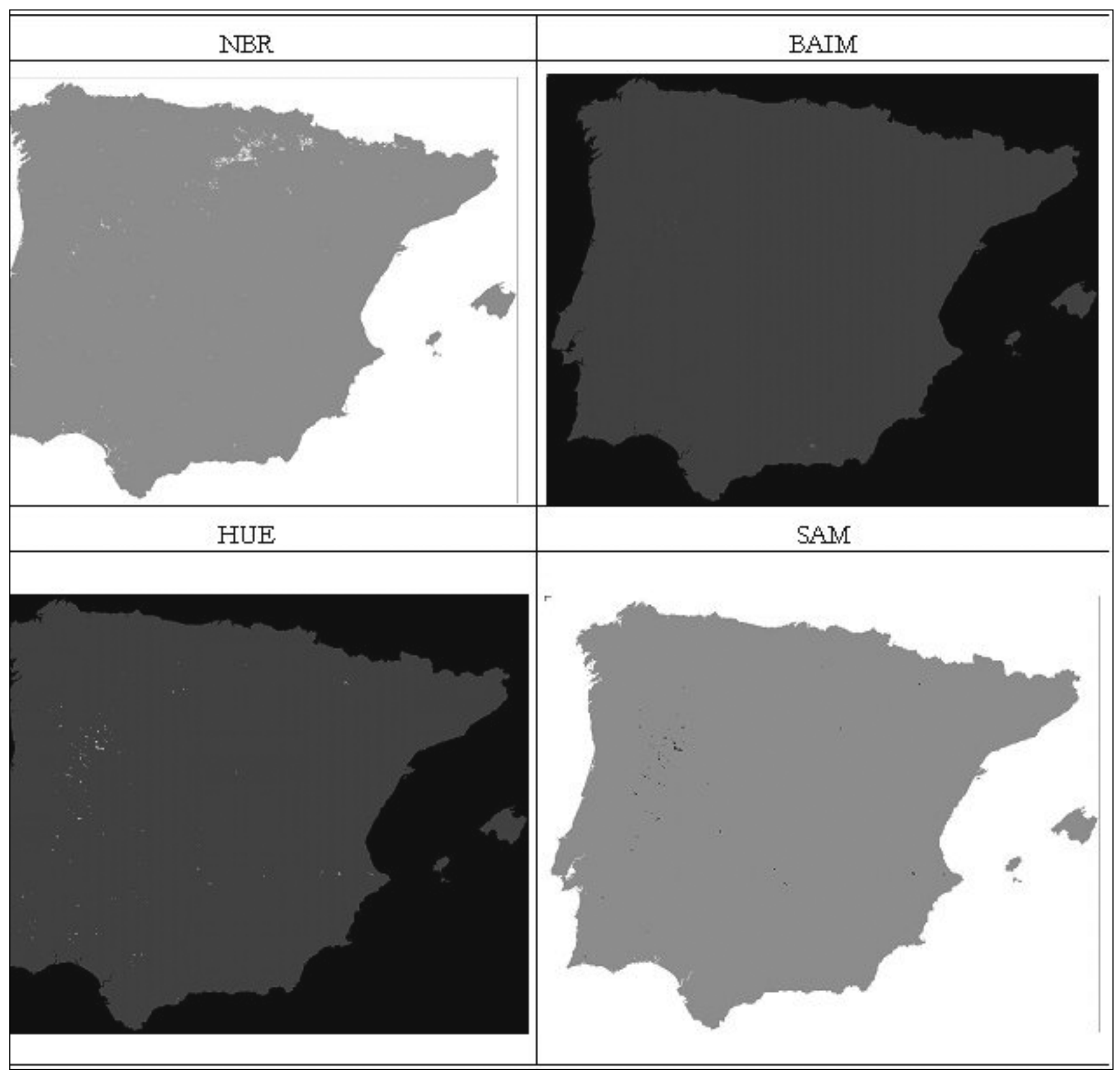

sión, y al mismo tiempo, muestra el error de comisión más bajo.

En la Figura 5 los resultados finales de la cartografía correspondientes al área de validación.

\section{DISCUSIÓN DE LOS RESULTADOS}

El cálculo de la separabilidad para las bandas del sensor utilizado, permite mejorar la discriminación de las áreas quemadas, dado que se concreta cuales son las bandas que ofrecen una mejor discriminación. De manera que la utilización de estas bandas para el cálculo de los índices o su aplicación en diferentes técnicas de clasificación mejora la información utilizada para la cartografía de área quemada.
En la figuras 4 se ha podido observar como HUE y SAM son sensibles a los incendios antiguos, al detectar los incendios que aparecen en la zona de Cataluña y Valencia. Mientras que BAIM no discrimina dichos incendios, esto se debe a que BAIM presenta los valores más elevados en aquellos píxeles con una señal más intensa de carbón, la cual se hace menor con el paso del tiempo. Por ello, estos incendios no presentan ningún píxel semilla, y por lo tanto no son clasificados como área quemada.

Los errores de comisión para SAM (15,4\%) se encuentran por debajo del índice BAIM (18,5\%), que está diseñado de forma exclusiva para MODIS, lo que resalta la importancia del uso de índices que no se basen en imágenes concretas. Si bien es cierto que los errores de omisión son muy similares. 


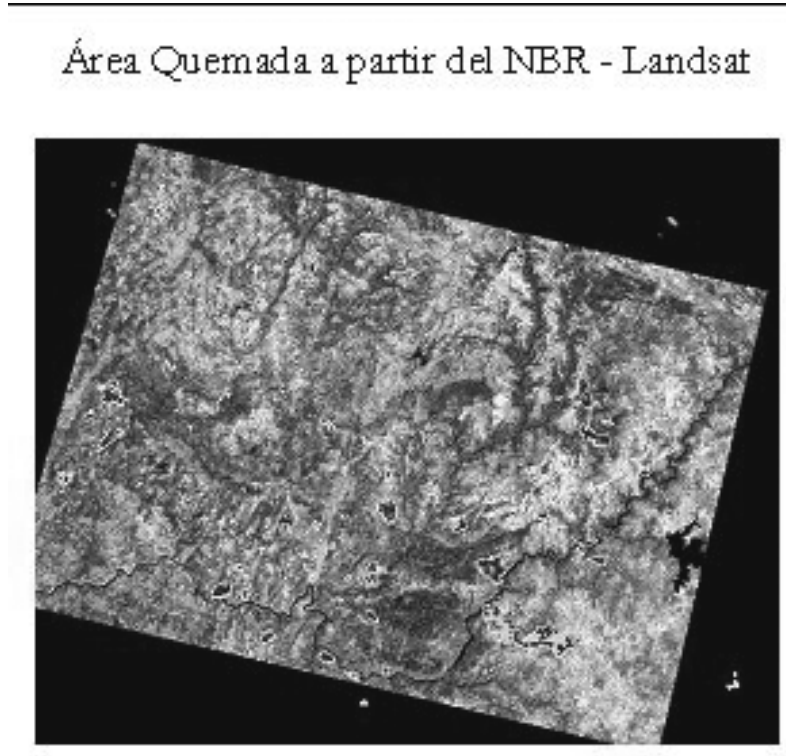

Área Quemada a partir del HUE - Landsat

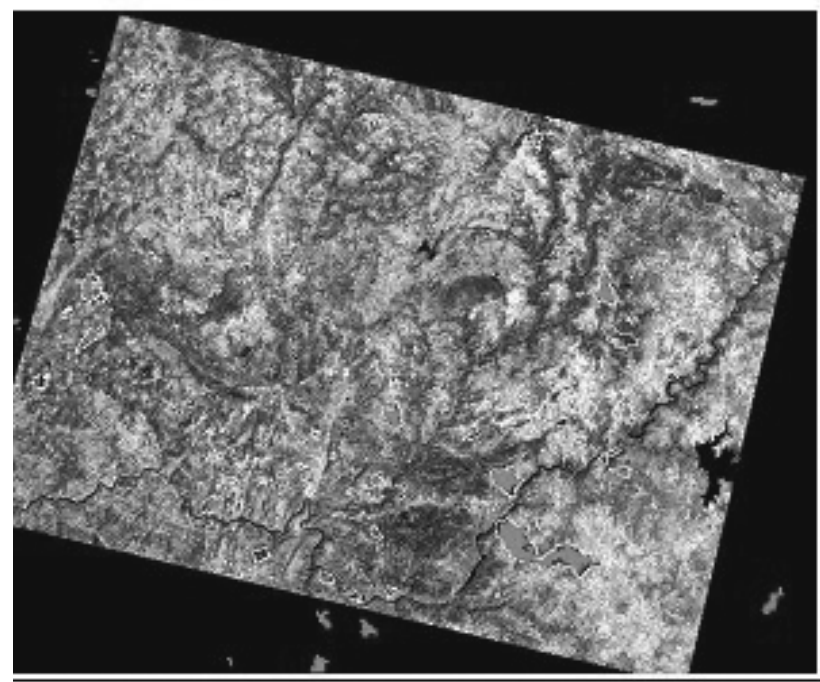

Un resultado sorprendente es el error de omisión del NBR (78\%) que se contradice con los obtenidos por otros autores para la cartografía de áreas quemadas de otras regiones del mundo (Li et al., 2004a), ya que ofrece los valores más altos de omisión. Sin embargo, el error de comisión del NBR, es el más bajo de todos los índices, aunque este resultado no se corresponde con el análisis visual de toda la península, ya que se puede observar que discrimina como quemado una gran zona en el norte de la península que realmente no es quemado. Estos errores se sitúan en zonas de montaña con escasa vegetación, por lo tanto se pueden justificar por la dificultad que este índice puede tener para discriminar entre suelo desnudo y área quemada.

Para BAIM los resultados son similares a los esperados (Martín et al., 2005), el elevado error de omisión es debido a
Área Quemada a partir del BAI - Landsat

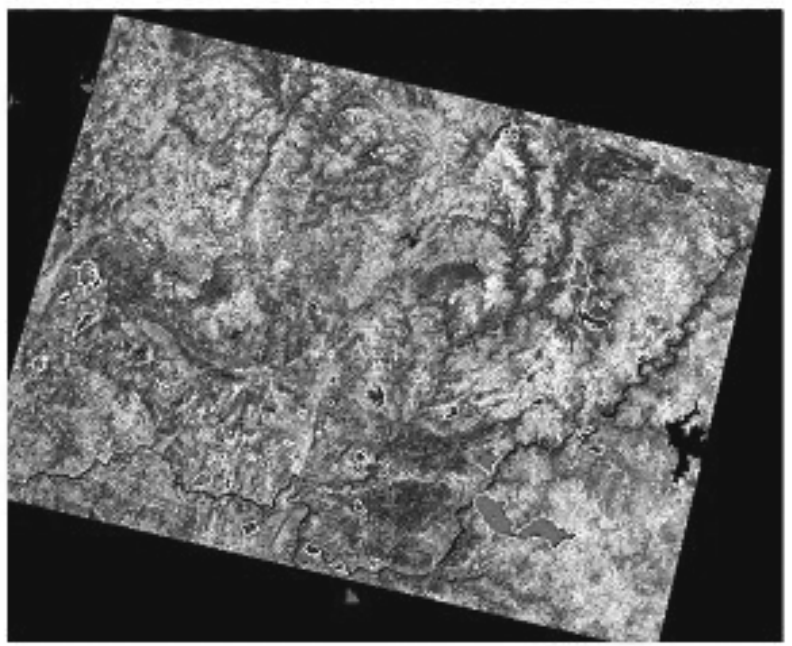

Área Quemada a partir del SAM - Landsat

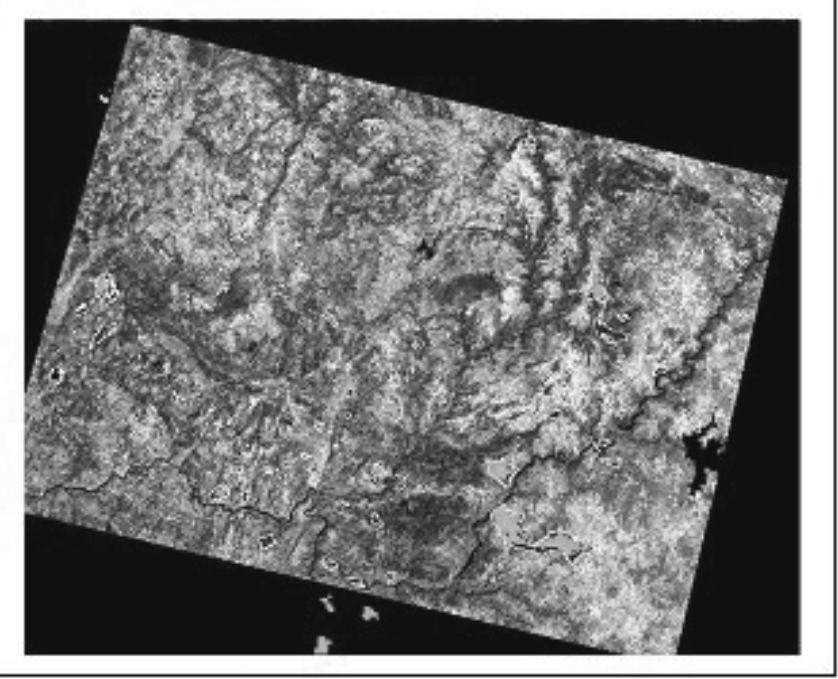

que más de la mitad de las áreas quemadas utilizadas en la validación presentan un área inferior a 100ha, que unido a la propia resolución espacial de MODIS (500×500m), dificulta la discriminación de dichos incendios.

Es importante notar que en el caso de las imágenes MODIS de 500 metros de resolución espacial, el área mínima cartografiable (correspondiente a un píxel) sería de 25 ha. Este es un factor limitante importante en la detección de los incendios más pequeños. De manera que, aquellos incendios que tengan un tamaño por debajo de las $25 \mathrm{ha}$, probablemente no serán detectados. Por otro lado, entre 25 y 100 hectáreas pueden aparecer ciertas dificultades en su detección, pues el valor que adquiere el pixel dependerá de la señal del incendio y del porcentaje de área quemada que se incluya dentro de cada píxel. 
Por último, hay que destacar que la imagen utilizada para la validación se refiere a una pequeña zona respecto a la superficie total de la Península, de manera que los errores de omisión y comisión calculados sirven para realizar una aproximación pero no serían concluyentes, ya que queda mucha superficie sin validar.

\section{CONCLUSIONES}

En líneas generales, se puede decir que tanto SAM como el componente HUE del IHS presentan muy buenos resultados y que se demuestra su gran potencial para la cartografía de área quemada. Tal vez, sería conveniente el estudio de su viabilidad a escalas supranacionales, dado que son capaces de discriminar como quemado toda la variabilidad espectral de las áreas quemadas más allá de la temporada de incendios. Así mismo se estima que la utilización de estos indices puede ser operativa para la creación de productos de área quemada.

\section{BIBLIOGRAFÍA}

Barbosa, P. M., J. San-Miguel Ayanz, B. Martínez y G. Schmuck (2002): Burnt area mapping in southern Europe using irs-wifs, en Forest Fire Research \& Wildland Fire Safety (editado por Viegas). Rotterdam, Millpress.

Chuvieco, E. (2002): Teledetección Ambiental: La observación de la Tierra desde el Espacio, Barcelona, Ariel Ciencia.Ariel Ciencia

Chuvieco, E., M. P. Martín y A. Palacios (2002a): Assessment of different spectral indices in the red-near-infrared spectral domain for burned land discrimination. International Journal of Remote Sensing, 23: 5103-5110.

Chuvieco, E., M. P. Martin y G. Ventura (2002b): Evaluación de imágenes NOAA-AVHRR y Terra-MODIS para cartografia regional de áreas quemadas, X Simposio Internacional de la Sociedad de Expertos Latinoamericanos en Percepción Remota (SELPER), Cochabamba, Bolivia.

Debba, P., F. J. A. van Ruitenbeek, F. D. van der Meer, J. M. Carranza y A. STEIN (2005): Optimal field sampling for targeting minerals using hyperspectral data. Remote Sensing of Environment, 99: 373-386.

Dennison, P. E., A. Roberts Dar, S. H. Peterson y J. Rechel (2005): Use of Normalized Difference Water Index for monitoring live fuel moisture content. International Journal of Remote Sensing, 26: 10351042.

FRASER, R. H., Z. LI y R. LANDRY (2000): SPOT Vegetation for Characterising Boreal Forest Fires. International Journal of Remote Sensing, 21: 3525-3532.

Garcia, M. y E. Chuvieco (2004): Assessment of the potential of SACC/MMRS imagery for mapping burned areas in Spain. Remote Sensing of Environment, 92: 414-423.

Giglio, L., J. Descloitres, C. O. Justice y J. B. Kauffmam (2003): An Enhanced Contextual Fire Detection Algorithm for MODIS. Remote Sensing of Environment, 87: 273-282.

GrÉGOIRE, J. M., K. TANSEY y J. M. N. SILVA (2003): The GBA2000 initiative: Developing a global burned area database from SPOT-VEGETATION imagery. International Journal of Remote Sensing, 24: 1369-1376.

Huete, A. R. (1988): A soil-adjusted vegetation index (SAVI). Remote Sensing of Environment, 25: 295-309.

JUSTICE, C. O., L. GIGLIO, et al., (2002a): The MODIS fire products. Remote Sensing of Environment, 83: 244-262.
JUsticE, C. O., J. R. G. TownSHEnd, et al., (2002b): An overview of MODIS Land data processing and product status. Remote Sensing of Environment, 83: 3-15.

JUSTICE, C. O., E. VERMOTE, et al., (1998): The Moderate Resolution Imaging Spectroradiometer (MODIS): Land Remote Sensing for Global Change Research. IEEE Transactions on Geoscience and Remote Sensing, 36: 1228-1249.

KeY, C. H. y N. Benson (2005): Landscape Assessment: Ground measure of severity, the Composite Burn Index; and Remote sensing of severity, the Normalized Burn Ratio., en FIREMON: Fire Effects Monitoring and Inventory System (editado por D. C. Lutes, R. E. Keane, J. F. Carattiet al). Ogden, UT, USDA Forest Service, Rocky Mountain Research Station, Gen. Tech. Rep. RMRS-GTR-164: CD: LA1-LA51.

KOUTSIAS, N. y M. KARTERIS (1998): Logistic regression modelling of multitemporal Thematic Mapper data for burned area mapping. International Journal of Remote Sensing, 19: 3499-3514.

KOUTSIAS, N. y M. KARTERIS (2000): Burned area mapping using logistic regression modeling of a single post-fire Landsat- 5 Thematic Mapper image. International Journal of Remote Sensing, 21: 673-687.

KoutSIAS, N., M. KaRTERIS y E. ChuvieCo (1999): Burnt land mapping at local scale, en Remote sensing of large wildfires in the European Mediterranean basin (editado por E. Chuvieco). Berlin, Germany, Springer-Verlag: 123-138.

KoutsiAs, N., M. KARTERIS y E. ChuvieCo (2000): The use of intensity-huesaturation transformation of Landsat-5 Thematic Mapper data for burned land mapping. Photogrammetric Engineering and Remote Sensing, 66: 829-839.

LI, R.-R., Y. J. Kaufman, W. M. HaO, J. M. Salmon y B.-C. Gao (2004a): A technique for detecting burn scars using MODIS data. IEEE Transactions on Geoscience and Remote Sensing, 42: 1300-1308.

LI, R. R., Y. J. KaUfman, W. M. HaO, J. M. SAlmon y B. C. GaO (2004b): A Technique for Detecting Burn Scars Using MODIS Data. IEEE Transactions on Geoscience and Remote Sensing, 42: 1300-1308.

López Garcia, M. J. y V. CAselles (1991): Mapping Burns and Natural Reforestation Using Thematic Mapper Data. Geocarto International, 1: 31-37.

MARTín, M. P. (1998): Cartografía e inventario de incendios forestales en la Península Ibérica a partir de imágenes NOAA-AVHRR, Departamento de Geografía, Alcalá de Henares, Universidad de Alcalá.

Martín, M. P. y E. Chuvieco (1998): Cartografía de grandes incendios forestales en la Península lbérica a partir de imágenes NOAA-AVHRR. Serie Geográfica, 7: 109-128.

Martin, M. P., R. Diaz Delgado, E. Chuvieco y G. Ventura (2002): Burned land mapping using NOAA-AVHRR and TERRA-MODIS, IV International Conference on Forest Fire Research. 2002 Wildland Fire Safety Summit, Luso, Coimbra, Portugal, Millpress: 45.

Martín, M. P., I. Gómez y E. Chuvieco (2005): Performance of a burnedarea index (BAIM) for mapping Mediterranean burned scars from MODIS data, en Proceedings of the 5th International Workshop on Remote Sensing and GIS applications to Forest Fire Management: Fire Effects Assessment (editado por J. Riva, F. Pérez-CabelloyE. Chuvieco). Paris, Universidad de Zaragoza, GOFC-GOLD, EARSeL: 193-198.

PereIRA, J. M. C. (1999): A Comparative Evaluation of NOAA/AVHRR Vegetation Indexes for Burned Surface Detection and Mapping. IEEE Transactions on Geoscience and Remote Sensing, 37: 217-226.

Pereira, J. M. C., E. ChuvieCo, A. Beudoin y N. Desbois (1997): Remote Sensing of burned areas: a review, en A review of remote sensing methods for the study of large wildland fires (editado por E. Chuvieco). Alcalá de Henares, Departamento de Geografía, Universidad de Alcalá: 127-184.

Pereira, J. M. C., A. C. L. SA, A. M. 0. Sousa, M. P. Martín y E. Chuvieco (1999a): Regional-scale burnt area mapping in Southern Europe using NOAA-AVHRR $1 \mathrm{~km}$ data, en Remote Sensing of Large Wildfires in the European Mediterranean Basin (editado por E. Chuvieco). Berlin, Springer-Verlag: 139-155. 
Pereira, J. M. C., A. C. L. SA, A. M. O. SousA, J. M. N. Silva, T. N. Santos y J. M. B. CARREIRAS (1999b): Spectral characterisation and discrimination of burnt areas, en Remote Sensing of Large Wildfires in the European Mediterranean Basin (editado por E. Chuvieco). Berlin, Springer-Verlag: 123-138.

PereirA, M. C. y A. W. Setzer (1993): Spectral characteristics of fire scars in Landsat-5 TM images of Amazonia. International Journal of Remote Sensing, 14: 2061-2078.

PINTY, B. y M. M. VERSTRAETE (1992): GEMI:a non-linear index to monitor global vegetation from satellites. Vegetatio, 101: 15-20.

Rogan, J. y J. FrankLIN (2001): Mapping wildfire burn severity in Southern California Forests and shrublands using enhanced Thematic Mapper imagery. Geocarto International, 16: 89-99.
RoY, D. P., L. Giglo, J. D. Kendall y C. O. Justice (1999): Multi-temporal active-fire based burn scar detection algorithm. International Journal of Remote Sensing, 20: 1031-1038.

RoY, D. P., Y. JIN, P. E. LEWIS y C. O. JUSTICE (2005a): Prototyping a global algorithm for systematic fire-affected area mapping using MODIS time series data. Remote Sensing of Environment, 97: 137-162.

Vázouez, A., J. M. Cuevas y F. González-Alonso (2001): Comparison of the use of WiFS and LISS images to estimate the area burned in a large forest fire. International Journal of Remote Sensing, 22: 901907. 


\title{
Validation and comparison of modis and aatsr active fire products in Spain in 2003
}

\author{
Patricia Oliva $^{1^{*}}$, Sara Jurdao ${ }^{2 *}$, Jesús Martínez ${ }^{3}$ y Emilio Chuvieco ${ }^{4}$. \\ Recibido 26/10/2007; aceptado el 20/01/2008
}

Resumen. A partir del tratamiento de los productos MODIS y AATSR para la detección de incendios activos, y de su comparación con las estadísticas oficiales aportadas por la DGB (Dirección General de la Biodiversidad), se han obtenido los resultados a través de los cuales se ha establecido la fiabilidad de los productos para la España Peninsular y Baleares en el 2003. La eficiencia se evaluó a través del cálculo de los errores de omisión y comisión, analizando la distribución espacio-temporal. Atendiendo a los resultados obtenidos, es posible afirmar que la fiabilidad mejora en relación proporcional al tamaño de incendio y tras realizar la comparación entre los productos se concluye que la detección es más precisa a través del sensor MODIS.

Palabras clave: MODIS, AATSR, DGB, Focos Activos, Error de Omisión.

Abstract. On the basis of the application of the MODIS and AATSR products for the detection of active fires and of their comparison with official statistics provided by the DGB (the State Biodiversity Office), results have been obtained by which the reliability of the products for the Iberian Peninsula and Baleares Islands in 2003 has been established. Their efficiency was evaluated by reckoning the errors of omission and commission, analysing the space-time distribution. On the basis of the results obtained it is possible to state that reliability improves in proportion to the size of the fire and, having made a comparison of the products, the conclusion has been reached that detection by the MODIS product is more accurate.

Key Words: MODIS, AATSR, DGB, Active fires, Omission Error.

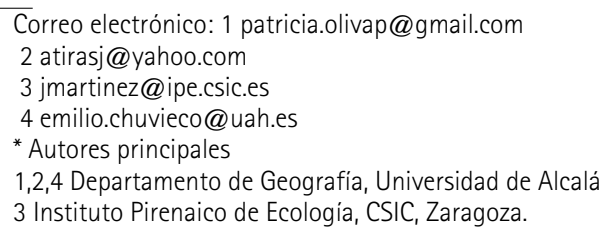




\section{INTRODUCCIÓN}

Los incendios forestales son un agente natural en el clima mediterráneo, sin embargo su repercusión en los últimos años está más allá de los ciclos naturales. Durante la última década ha aumentado la superficie quemada, no sólo por el incremento del número de incendios, sino también, por la mayor cantidad de biomasa acumulada en los bosques que facilita la propagación del frente de llama.

Para actuar con la mayor rapidez posible contra los incendios forestales, y realizar estudios sobre los patrones de ocurrencia de los mismos, se hace necesario conocer la localización de los focos de ignición. Con este fin se han desarrollado diferentes técnicas entre las que destaca el empleo de la teledetección espacial (Ahern et al., 2001).

En este marco, varios autores han abordado la detección de incendios activos a partir de imágenes de satélite, principalmente a escala regional y global (Ahern et al., 2001). La base física para reconocer un incendio activo se centra en la alta emitancia que presenta un foco muy caliente en el infrarrojo medio (especialmente entre 3 y $5 \mu \mathrm{m}$ ), a consecuencia de la ley de Wien. Numerosos proyectos se han basado en imágenes de esta banda del espectro para la detección de focos de incendio activos. Hasta hace unos años, el sensor más empleado ha sido sin duda el AVHRR (Cracknell, 1997), a bordo de la serie de satélites NOAA. Este sensor, operativo desde 1979, cuenta con una banda de observación en torno a 3.7 $\mu \mathrm{m}$ que se ha utilizado extensivamente para cartografiar incendios activos, si bien estaba diseñada con otro propósito, lo que la hace saturarse con facilidad (Martín et al., 1999). Trabajando en una banda algo más corta, los sensores ATSR y AATSR a bordo de los satélites europeos ERS y Envisat también se han utilizado para detección de incendios activos, de cara a evaluar el impacto del fuego a escala planetaria (Arino y Melinotte, 1998). Con otro enfoque complementario, los datos nocturnos del satélite DMSP también han ofrecido una información de gran interés sobre incendios activos, aunque en este caso se observa no el calor, sino la luz desprendida por estos eventos (Elvidge, 2001). Más recientemente, el sensor MODIS se está empleando globalmente con esta misma finalidad, gracias a disponer de varios canales en el infrarrojo medio y térmico. Entre los productos estándar de este sensor se cuenta uno dedicado especificamente a incendios activos (Justice et al., 2002), que se está utilizando en numerosos estudios de escala global. Los satélites geoestacionarios también resultan de gran potencial en esta aplicación, gracias a su alta frecuencia de observación. Los GOES han incluido un canal en el infrarrojo medio desde hace más de una década, lo que ha permitido su utilización en la detección de incendios en América (Prins y Menzel, 1992). El lanzamiento del Meteosat de Segunda Generación abre nuevas posibilidades para esta aplicación, ya que cuenta con varios canales en el infrarrojo medio y ofrece alta sensibilidad radiométrica (Pereira y Go- vaerts, 2001). Finalmente, resulta imprescindible citar las misiones específicas de detección de incendios que se han propuesto en los últimos años, singularmente el programa Fuego-Sat y el BIRD (Martínez et al., 2000), aunque ninguna es todavía operativa.

\section{OBJETIVOS}

Este artículo tiene por objetivo evaluar la fiabilidad de dos productos de detección de incendios activos, que se generan de modo operativo y a escala planetaria por los sensores MODIS y AATSR. Con este fin, se han tomado como referencia las estadisticas oficiales de la Dirección General de Biodiversidad (DGB), organismo dedicado a la gestión de incendios forestales, dentro del Ministerio de Medio Ambiente. Por último, se compararán los resultados obtenidos por ambos sensores para determinar el de mayor fiabilidad.

\section{METODOLOGÍA}

La metodología de este trabajo se ha basado en tres etapas. En la primera se han obtenido los productos de incendios activos de los sensores AATSR y MODIS, procediéndose a su espacialización y ajuste a un formato común. En la segunda etapa, se han tratado las estadísticas de incendios facilitadas por la DGB atendiendo a diferentes tamaños de incendio. La validación de los productos de ambos sensores se ha abordado a través del cálculo de una matriz de confusión tomando como datos de referencia los extraídos de las estadísticas oficiales, y finalmente, se ha determinado cuál de los dos ofrece mayor exactitud.

En este estudio, desarrollado para el territorio peninsular y Baleares, se han establecido tres escalas temporales de trabajo: semanal, estacional y anual. El análisis anual ha sido referido al año 2003. Para realizar el estudio a escala estacional, se ha prestado especial atención a la estación de incendios, considerando los meses de Junio, Julio, Agosto y Septiembre. Por último, se ha llevado a cabo un estudio pormenorizado de la temporada de incendios considerando la escala semanal. Debido a las características del producto MODIS de reflectividad utilizado, se consideran como "semanas" periodos de 8 días de duración.

1. Adquisición y tratamiento de los productos de incendios activos

\section{Sensor AATSR}

Los datos para este trabajo se han extraído de dos productos operativos que se calculan diariamente a escala planetaria. El primero de ellos se denomina ATSR World Fire Atlas (http://dup.esrin.esa.int/ionia/wfa/index.asp). Se trata de una serie temporal que recoge los incendios activos detectados por los sensores ATSR-2 (Along Track Scanning 
Radiometer), a bordo del ERS-2, desde 1995 hasta 2002, y del AATSR (Advanced Along Track Scanning Radiometer), instalado en el Envisat, desde el 2003 hasta la actualidad. Para este trabajo, hemos empleado la serie disponible para el año 2003, que se basa en datos AATSR. Éste adquiere imágenes en 7 bandas espectrales (centradas en $0.55,0.66$, $0.87,1.6,3.7,11$ y $12 \mu \mathrm{m}$ ), en dos ángulos (vertical y hacia delante), con una resolución en el nadir de $1 \mathrm{~km}$, y de hasta 1-5x2 km en la visión delantera (http://envisat.esa.int/ instruments/aatsr/). La detección de incendios activos a partir de este sensor se hace únicamente a partir de las imágenes nocturnas, empleando dos algoritmos basados en umbrales sobre la banda de $3.7 \mu \mathrm{m}$. La detección teórica que estiman los autores está en incendios de 0,1 Ha cuando están a una temperatura próxima a los $600 \mathrm{~K}$, y de 0,01 $\mathrm{Ha}$ cuando alcanzan los $800 \mathrm{~K}$, considerando una temperatura de fondo de $300 \mathrm{~K}$. Las limitaciones de estos algoritmos se relacionan con la presencia de nubes; los efectos atmosféricos; la bidireccionalidad del algoritmo de emisividad; y que la temperatura y la extensión del fuego no están considerados en el proceso. Al considerarse únicamente los incendios nocturnos se evitan posibles confusiones con suelos calientes, pero se reduce la detectatibilidad de los fuegos de ciclo corto. Para este proyecto hemos seleccionado los productos derivados del algoritmo 1, que retiene únicamente los píxeles que alcanzan el nivel de saturación del sensor (312 K).

Una vez descargados los datos en formato ASCII correspondientes a 2003, a partir del servidor del ATSR World Fire Atlas, se procedió a seleccionar los correspondientes a la Península lbérica y Baleares mediante una base de datos relacional. Posteriormente, se importaron a un Sistema de Información Geográfica (Arcview) para referenciarlos a una proyección común con los datos MODIS y las estadísticas de la DGB. Los datos se agruparon por semanas de ocho dias para facilitar la comparación con el producto estándar MODIS. En el año seleccionado, este sensor no detectó incendios en nuestro país para los meses de febrero, noviembre y diciembre.

\section{Sensor MODIS}

El segundo producto de detección de incendios que se ha utilizado para este proyecto es el generado operativamente a partir de datos del sensor MODIS (Moderate Resolution Imaging Spectroradiometer). Este sensor orbita en los satélites TERRA (1999) y AQUA (2001). El sensor MODIS tiene 36 canales, 2 con una resolución espacial de $250 \mathrm{~m}$, cinco con una resolución de $500 \mathrm{~m}$ y el resto con una resolución de $1 \mathrm{~km}$, que se sitúan entre unas longitudes de onda de $0.4 \mu \mathrm{m}$ hasta $14.4 \mu \mathrm{m}$ (Guenther et al., 2002; http://M0DIS.gsfc. nasa.gov/). El producto que se ha empleado es el denominado MOD14A2, que recoge las anomalias térmicas con resolución de $1 \mathrm{~km}^{2}$ para un intervalo de 8 dias. Este producto se genera utilizando las bandas de 4 y $11 \mu \mathrm{m}$, para la detección, y las bandas del visible e infrarrojo cercano (de mayor resolución) para determinar la cobertura de nubes (http://modis-fire.umd.edu/). El algoritmo empleado se basa en una secuencia de umbrales múltiples y criterios de contexto, y funciona tanto de día como de noche (Giglio et al., 2003).

Una vez obtenido el producto del servidor de Internet del programa MODIS, se realizó un mosaico de las imágenes a partir de cuatro bloques (tiles) estándar, con objeto de completar la superficie de la Península y Baleares. Posteriormente, se reproyectó la imagen a proyección UTM 30 (Datum Europeo 1950), para superponer los datos con la cuadrícula de la DGB, empleada para referenciar incendios.

\section{Adquisición y tratamiento de estadísticas de incendio}

Se realizó una petición a la DGB para obtener los partes informatizados de incendios acaecidos en el año 2003, lo que suponía procesar 18.000 registros. A través de consultas en una base de datos relacional, se resumieron las variables que incluian estos registros extrayendo las que resultaban de utilidad para este proyecto. La unidad de referencia para la DGB es la cuadrícula de la rejilla UTM de $10 \times 10 \mathrm{~km}$, lo que supone el nivel de referencia más detallado que podemos utilizar para comparar con los incendios extraídos de las imágenes.

A partir de la base de datos de partes de incendio, se contabilizó el número de incendios iniciados para cada una de esas cuadrículas, distinguiendo entre cuatro tamaños de incendios: de 0 a 5 has, de 5 a 100 has, de 100 a 500 has y mayores de 500 has. Estas clases nos permitirian evaluar si la detección de incendios realizada a partir de satélite ofrecía resultados significativamente distintos en función del tamaño del incendio. A priori sería lógico pensar que a mayor tamaño de incendio, aumentaría la probabilidad de su detección. Sin embargo, esto no es tan evidente si se tiene en cuenta que el satélite sólo detecta la situación del incendio cuando es observado por el sensor. Por tanto, sólo se refiere al tamaño del foco activo en un determinado momento de su evolución y no a la superficie quemada.

Las estadisticas por cada cuadrícula $10 \times 10 \mathrm{~km}$ se agruparon también en periodos de 8 días, para facilitar la comparación con los productos de satélite. Lamentablemente, no es posible identificar qué incendios MODIS o AATSR se corresponden con cada registro de la $D G B$, ya que no se indican coordenadas exactas, sino sólo la cuadricula donde se ubica.

En resumen, se disponía de varios campos binarios (0/1), estableciendo la ausencia o presencia de incendio para cada cuadrícula, periodo temporal y tamaño de incendio. 


\section{Validación y comparación de los productos}

\section{Validación para todos los incendios}

Se han considerado como "incendios observados" los recogidos en la base de datos de la DGB y como uincendios detectados" los correspondientes a los obtenidos a partir de los productos MODIS y AATSR. Para ambos productos se ha realizado la espacialización de los focos activos a la cuadrícula de 10x10 km de la DGB, tomada como unidad de referencia.

Los resultados han sido obtenidos a partir de una tabulación cruzada (Tabla 1) entre las cuadrículas que cuentan con incendios detectados (o no), por los sensores, y las que tienen incendios observados (o no), por la DGB. A partir de esa comparación, se identificaron las cuadrículas de la rejilla UTM de 10x10 km que contaban con incendios detectados y observados o no detectados y no observados (aciertos), detectados y no observados (errores de comisión), y no detectados y observados (omisión). Considerando la limitación espacial de la base de datos de la DGB, es preciso interpretar con cautela tanto los errores de omisión como los de comisión. Al no saber exactamente si cada píxel detectado como incendio corresponde a uno o a varios incendios reales, se considera omisión aquella cuadrícula con incendio observado que no tienen ningún incendio detectado. Por otro lado, la comisión será la correspondiente a las cuadrículas en las cuales se han detectado incendios pero no han sido observados por la DGB, lo que puede ser consecuencia tanto de ruidos en la detección, como de problemas en la georeferenciación de las imágenes que incluyen ambos productos.

La notación de la fiabilidad total de la tabla de cruce entre los datos de la DGB y los detectados por satélite, puede expresarse de la siguiente forma:

$$
\hat{F}=\frac{\sum_{i=1, n} x_{i i}}{\sum_{i=1, n} \sum_{j=1, n} x_{i j}}
$$

donde $X_{i i}$ indica el acuerdo entre la detección por satélite y la observación por la DGB. Los errores de omisión y de comisión se formulan como:

$$
E_{0, i}=\frac{X_{+i}-X_{i i}}{X_{+i}}
$$

$$
E_{c, i}=\frac{X_{i+}-X_{i i}}{X_{i+}}
$$

donde $X_{+i}$ indica el total de incendios observados por la DGB $\mathrm{y}_{\mathrm{j}+}$ el total de los detectados en las imágenes AATSR o MODIS. En este caso, estariamos validando el error asociado a la detección. Otra cosa sería analizar el error asociado a la ausencia de detección, comparando los no detectados en las imágenes con los observados o no observados por la DGB. Lógicamente, en este segundo caso, los errores serian inferiores a los de la detección, ya que el fenómeno no incendio es mucho más frecuente que el fenómeno incendio.

En cuanto a la escala anual se ha realizado sin considerar el tamaño del incendio. Para el análisis estacional y semanal se han considerado las escalas de tamaño comentadas anteriormente, pero debido a la limitación de espacio existente, dichos mapas no se presentan en esta publicación.

Por último, además de los resultados numéricos obtenidos a partir de las tabulaciones cruzadas, se han construido mapas que representan los resultados de cruce entre cuadrículas.

\section{Validación en función del tamaño de incendio}

En los productos derivados de las imágenes, cuando se están validando todos los incendios pueden estimarse tanto los errores de omisión como los de comisión. Sin embargo, cuando se consideran los incendios por tamaños, sólo se puede estimar los errores de omisión, ya que los productos derivados de las imágenes son binarios, incendio-no incendio, y por tanto no nos informan sobre el tamaño del incendio. En consecuencia, no se podría saber si un incendio hipotéticamente considerado como error de comisión para una determinada clase de tamaño de incendio, podría estar detectado en otra categoría de tamaño.

\section{Análisis de los patrones de ocurrencia}

Puesto que estos sensores son de escala global, un último aspecto a considerar en nuestro análisis sería si los patrones espaciales de ocurrencia son similares a los detectados mediante estos sensores. En otras palabras, se trataría de comprobar si la distribución espacial de las cuadrículas con incendios detectados por AATSR o MODIS tiene un gra-

TABLA 1: Matriz de validación empleada

\begin{tabular}{|c|c|c|c|c|}
\hline \multirow{2}{*}{\multicolumn{2}{c|}{}} & \multicolumn{2}{|c|}{ DGB } & \\
\cline { 3 - 5 } \multicolumn{2}{c|}{} & OBSERVADO & NO OBSERVADO & \\
\hline \multirow{2}{*}{$\begin{array}{c}\text { AATSR } \\
\text { MODIS }\end{array}$} & DETECTADO & $11(\mathrm{ii})$ & $10(\mathrm{ji})$ & $\mathrm{i}+$ \\
\cline { 2 - 5 } & NO DETECTADO & $01(\mathrm{ij})$ & $00(\mathrm{jj})$ & $\mathrm{j}+$ \\
\cline { 2 - 5 } & & $+\mathrm{i}$ & $+\mathrm{j}$ & $\mathrm{TOTAL}$ \\
\hline
\end{tabular}


do aceptable de concordancia con las registradas por las estadísticas oficiales $y$, en consecuencia, si podrian utilizarse esos datos para obtener una visión global de las áreas más afectadas por incendios. Una manera de comprobar esta hipótesis sería calcular el grado de acuerdo entre detecciones reales y extraídas de los datos AATSR y MODIS, empleando el estadistico kappa ( $k$ ). Este índice se utiliza habitualmente para indicar el grado de fiabilidad entre los resultados de una clasificación y la verdad terreno. En el ámbito del presente artículo, indica si el acuerdo observado en la distribución espacial de la detección es significativamente mejor que el que puede obtenerse al azar y también si hay diferencias significativas entre ambos sensores. El estadistico $k$ se obtiene a partir de la siguiente fórmula (Hudson y Ramn, 1987):

$$
\hat{\kappa}=\frac{n \sum_{i=1, n} X_{i i}-\sum_{i=i, n} X_{i+} X_{+i}}{n^{2}-\sum_{i=i, n} X_{i+} X_{+i}}
$$

donde $\mathrm{n}$ sería el tamaño de la muestra, $X_{\mathrm{ii}}$ el acuerdo observado, $y$ el producto de los marginales $\left(X_{i+1} X_{+i}\right)$ el acuerdo esperado en cada categoría i. Para calcular la significación del estadistico, se ha utilizado la siguiente fórmula (Skidmore, 1989):

$$
z=\frac{\left|\hat{\kappa}_{1}-\hat{\kappa}_{2}\right|}{\sqrt{\sigma_{\kappa}{ }^{2}+\sigma_{\kappa 2}{ }^{2}}}
$$

Donde la varianza de $\mathrm{k}$ se obtiene a partir de Congalton y Mead (1983).

\section{RESULTADOS}

1. Resultados para todos los incendios

\section{Análisis anual}

De las 5265 teselas de $10 \times 10 \mathrm{~km}$ que cubren la España peninsular y Baleares, en el año 2003 se registraron incendios en 2686, considerando todos los tamaños y meses del año, lo que supone que algo más de la mitad del territorio nacional tuvo, en sus alrededores, algún fuego en algún momento del año (Figuras 1 y 2). Únicamente las zonas agrarias extensivas de la Meseta Norte y Sur, Valle del Guadalquivir y Depresión del Ebro, así como algunas sierras más elevadas y/o inaccesibles fueron exentas de incendios.

Sin embargo, de las 2686 teselas en las cuales se registraron incendios en el año 2003, sólo 59 fueron seleccionadas por los incendios detectados por el sensor AATSR, y 562 se identificaron a partir del sensor MODIS. En ambos casos, estos datos se refieren a teselas que se quemaron al menos una vez en el periodo de estudio, aunque puede ocurrir que tuvieran varios incendios en otros meses (dado el tamaño de estas teselas, esto es muy probable en las zonas de mayor ocurrencia, pues el total de incendios en el país superó los 18.600 en el año 2003). Las teselas con acierto (en la detección o en la no detección), implican que se observa al menos un incendio en esa tesela.

\section{ERROR DE OMISIÓN}

A partir de estas premisas, podemos calcular un error global de omisión para AATSR cercano al 98\%, mientras M0-

FigURA 1: Mapa anual de todos los incendios del sensor AATSR para el año 2003.

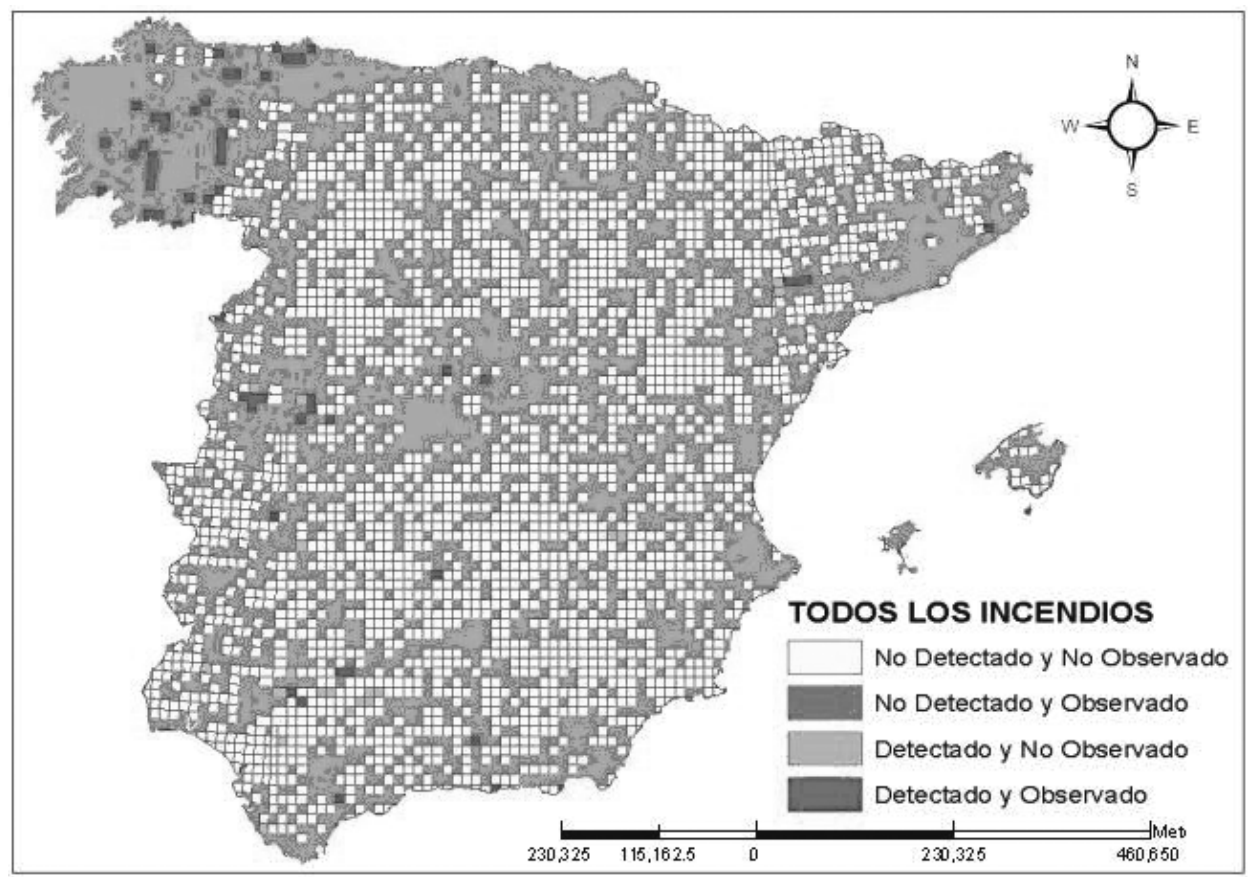


FIgURA 2. Mapa anual de todos los incendios del sensor MODIS para el año 2003.

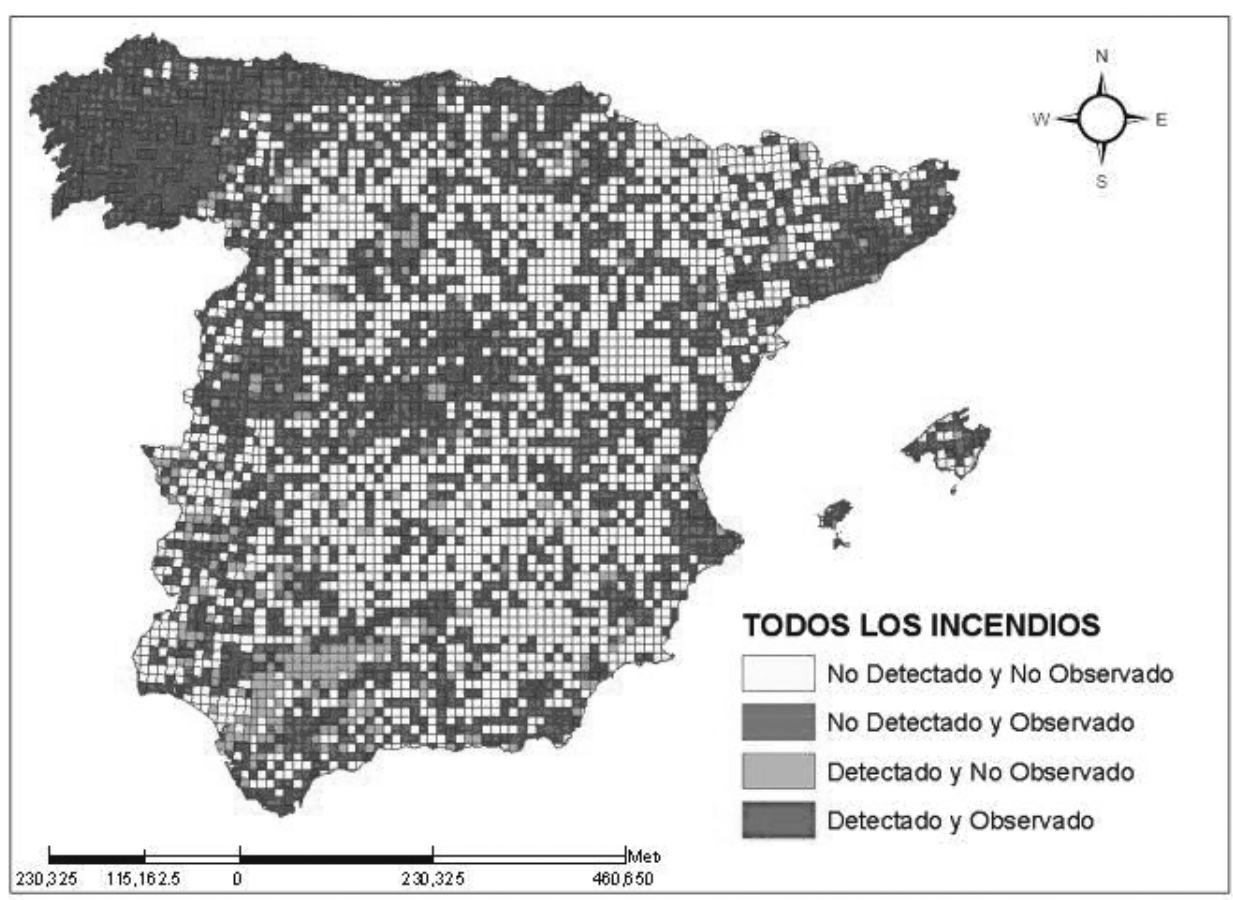

DIS lo reduce a algo menos del $80 \%$. Como venimos indicando a lo largo de este trabajo, estos errores se refieren no a incendios concretos, sino a al número de teselas que cubren el área de estudio.

\section{ERROR DE COMISIÓN}

Las estimaciones de los errores de comisión son mucho más confiables al indicar las teselas señaladas como incendio por alguno de los dos sensores en algún periodo del mes, pero que no han sido observados como incendio por la DGB en ningún periodo del mes. Por tanto, estamos bastante seguros que se trata de detecciones incorrectas. En este caso, la tasa de error es ligeramente superior en MODIS, con un $34 \%$, frente al $27 \%$ del AATSR. Esto parece razonable, ya que AATSR sólo detecta incendios por la noche, en donde las posibles confusiones de focos activos con suelos descubiertos, reflejos especulares o bordes de nubes tienden a reducirse mucho.

\section{Resultados en función del tamaño de incendio}

\section{Análisis estacional}

En el estudio desarrollado para la temporada de incendios, se observa una mejor discriminación de las teselas que han albergado los incendios más grandes (figura 3), si bien la mejora es mucho más significativa para MODIS que para AATSR. El primero ofrece valores de detección correcta cercanos al 60\% para las teselas con incendios mayores a 500 hectáreas, mientras se sitúa en torno al $20 \%$ para los menores a 5 hectáreas. Al igual que en el caso anterior, estos porcentajes se refieren a proporción de teselas en las que la detección y la observación coinciden.

\section{Análisis semanal}

Tras el análisis estacional, se ha profundizado la comparativa entre incendios detectados y observados en los periodos de ocho días desde junio hasta septiembre, cuando se produce el $70 \%$ de los incendios del año.

La figura 4 incluye el total de teselas que en cada periodo de ocho días incluyen algún incendio detectado por MODIS o AATSR. Como puede observarse, la detección con MODIS es mucho más detallada, frente al AATSR que resulta bastante conservador, al no detectar ningún incendio en algunos periodos de inicio de junio y julio, lo que se relaciona de nuevo con su exclusiva actividad nocturna, y con el umbral de saturación que es relativamente alto.

\section{SENSOR AATSR}

En cuanto al análisis de errores, AATSR (figura 5) muestra una tasa de omisión muy elevada, con valores superiores al $98 \%$ en todos los periodos del estudio. Conviene remarcar de nuevo que se trata de omisión en las teselas en donde hay incendios detectados en los ocho días del periodo, no de incendios propiamente dichos. Aunque la proporción puede estimarse que sería similar, no tenemos datos para comprobarlo. Si consideramos sólo las teselas con incendios obser- 
VALIDACIÓN Y COMPARACIÓN DE LOS PRODUCTOS MODIS Y AATSR PARA LA DETECCIÓN DE FOCOS ACTIVOS EN LA ESPAÑA PENINSULAR Y BALEARES...

FIgURA 3. Proporción de cuadrículas con incendios correctamente detectados para distintos tamaños de área quemada en la estación de incendios.

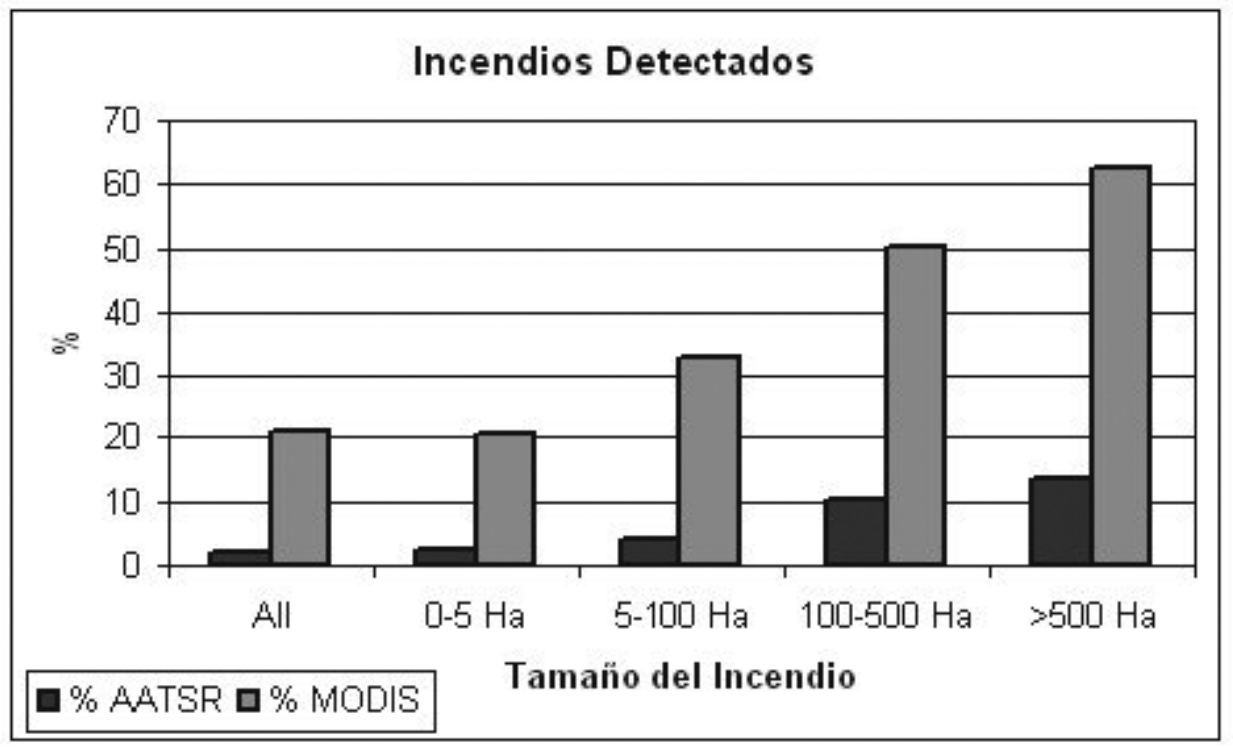

vados mayores de 100 hectáreas, la omisión desciende ligeramente, especialmente en las semanas centrales del verano, donde se alcanzan valores próximos al 90\% de error. En cuanto al error de comisión, muestra valores mucho más bajos, confirmando el carácter conservador del AATSR al realizar una detección nocturna (discrimina menos incendios, pero de modo más seguro que MODIS). Pueden aparecer esporádicamente errores de comisión muy altos cuando el nú- mero de incendios detectados es bajo, como ocurre al inicio del mes de septiembre, pero en general las falsas alarmas de este sensor son relativamente bajas.

\section{SENSOR MODIS}

El sensor MODIS (figura 6) muestra errores de omisión mucho más pequeños que el AATSR, especialmente cuando

FIGURA 4. Proporción de cuadrículas con incendios detectados por MODIS y AATSR en las semanas de la temporada de incendios.

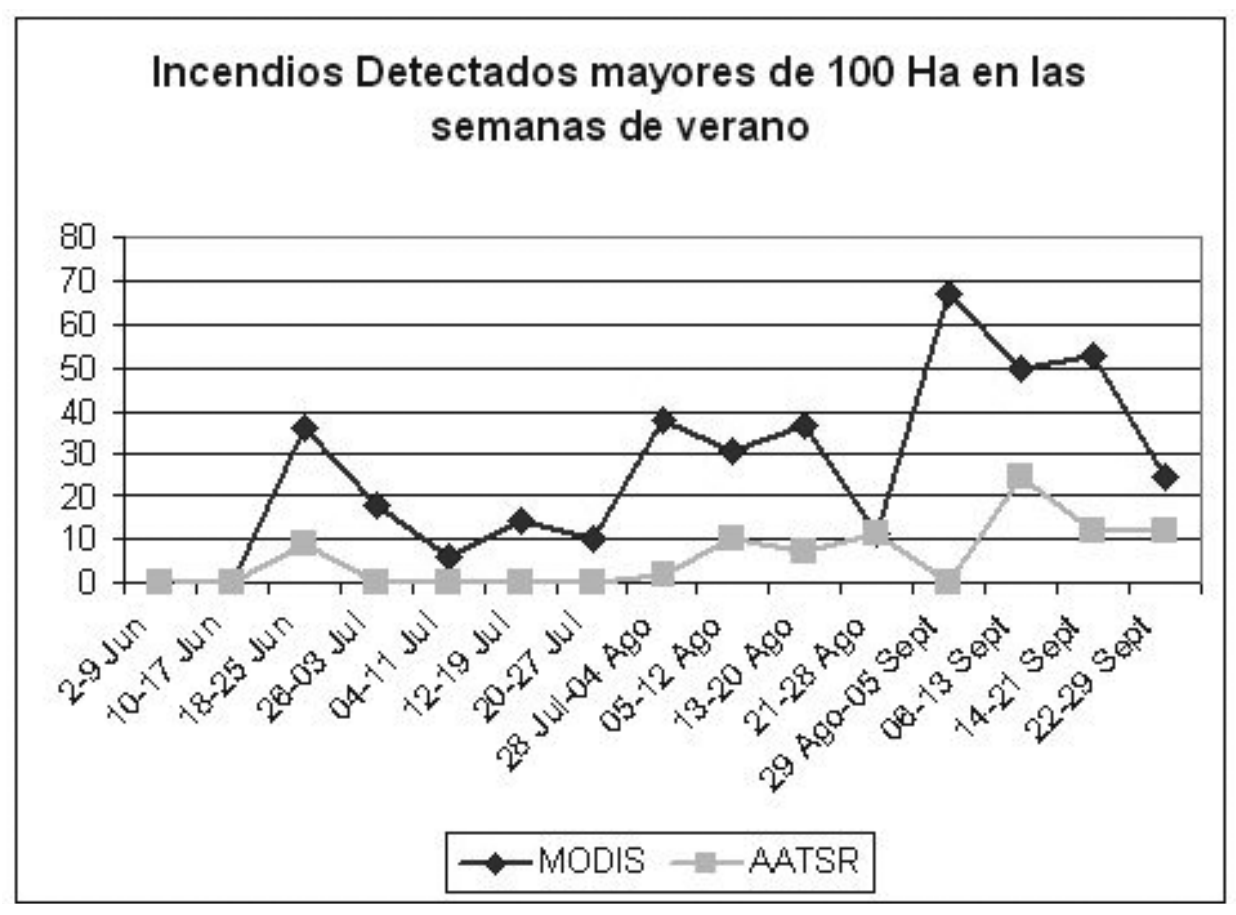


FIGURA 5: Errores de omisión y comisión para AATSR en las semanas de verano.

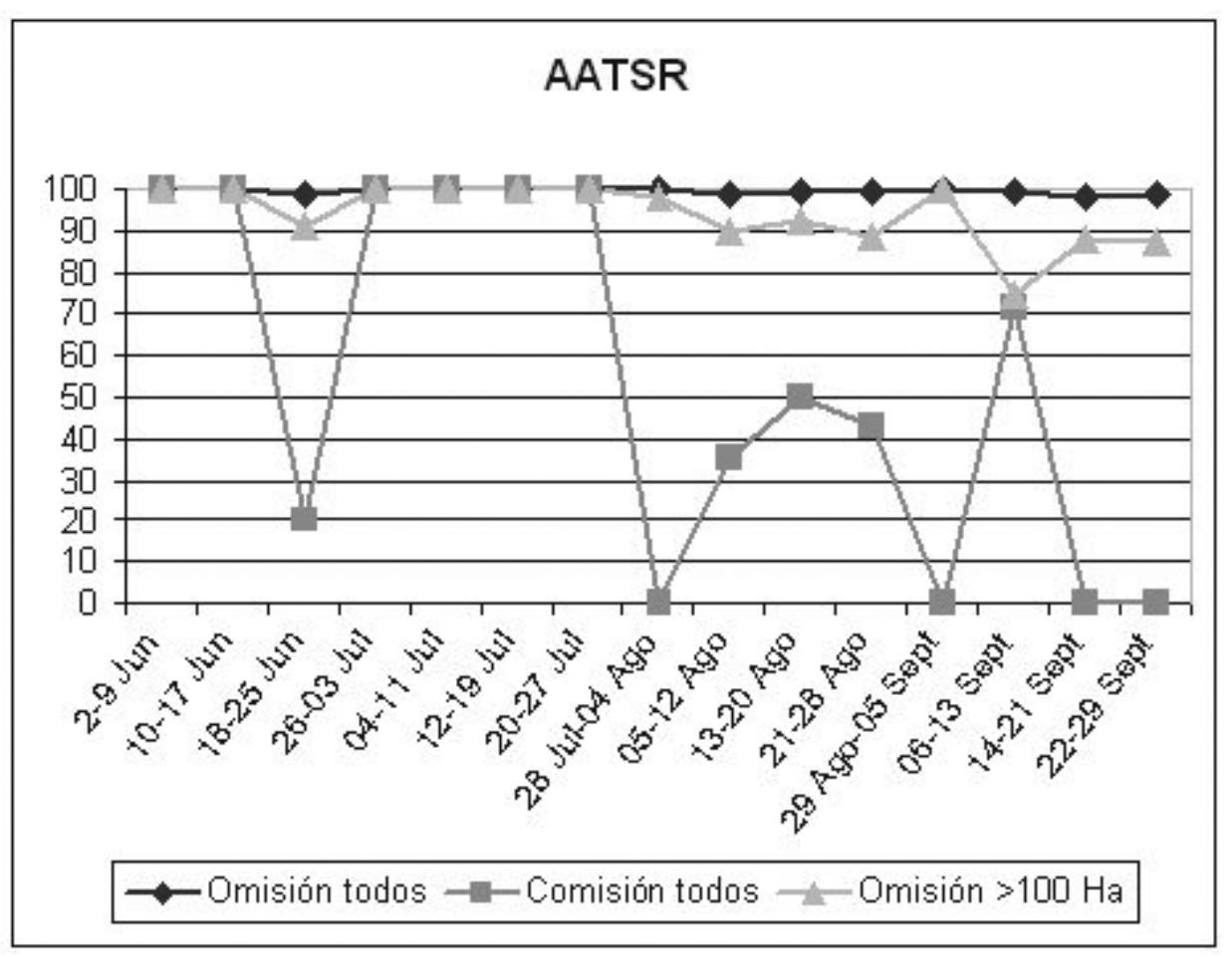

nos referimos a los incendios más grandes, en donde se alcanzan tasas de error de omisión cercanas al 30 \% en algunos periodos del verano, aunque son bastante fluctuantes. En cuanto a los errores de comisión, son más altos que para el AATSR (promedio 70\% para MODIS y 30\% para AATSR). Estos errores siguen el mismo patrón que los de omisión para los incendios > 100 hectáreas, presentando los valores más bajos durante el mes de agosto. Entendemos que buena parte de estos errores, tal y como se observa en la figura 2, se relacionan con quemas agrícolas de fin de temporada, por lo que no aparecen en las estadisticas oficiales de la DGB. No obstante, esos casos no pueden considerarse propiamente como falsas alarmas, ya que se trataria de incendios reales. Resulta muy complicado, con la información que se dispone

FIGURA 6: Errores de omisión y comisión para MODIS en las semanas de verano.

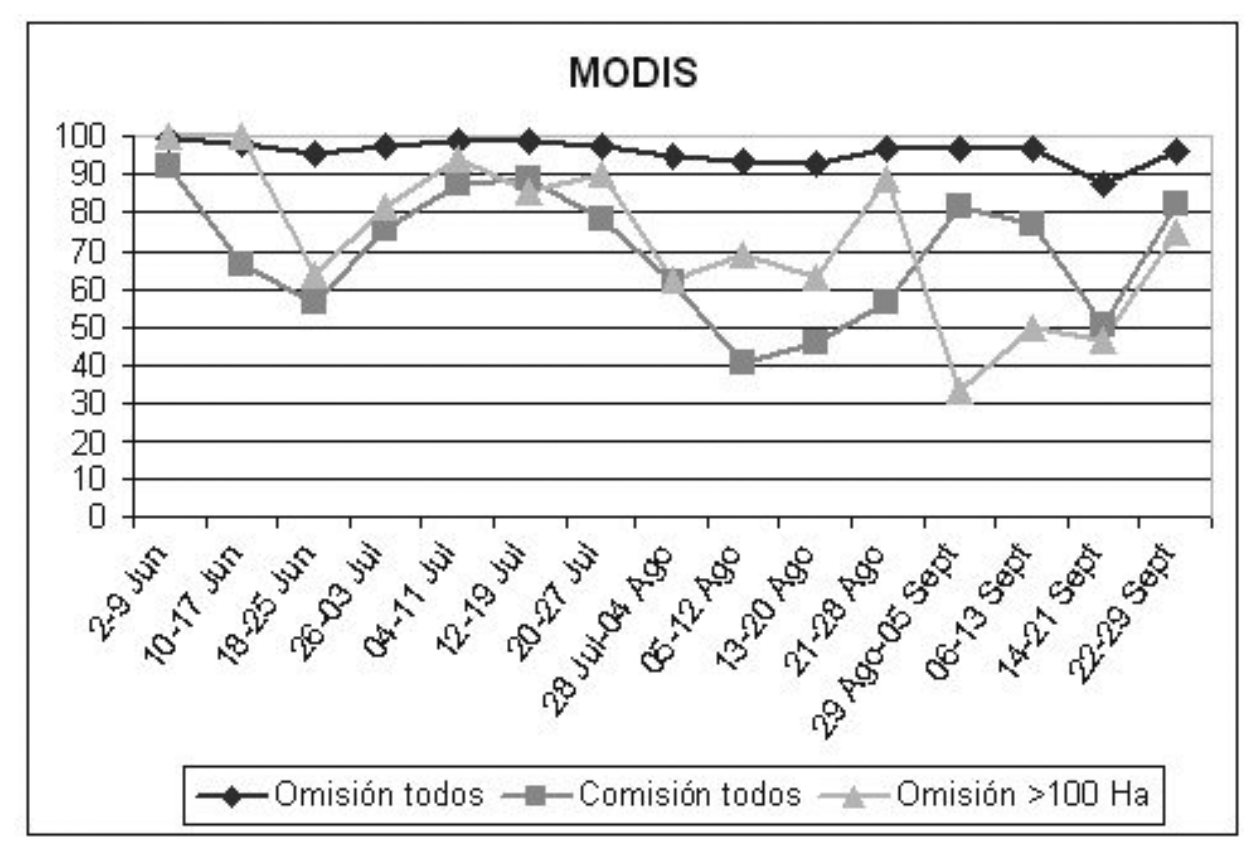


poder calcular qué proporción de los errores de comisión corresponde a este tipo de situaciones.

\section{Análisis de los patrones de ocurrencia}

La distribución espacial de los datos muestra las zonas del pais en las que la detección con los dos sensores es más acertada y aquellas en las que se observan errores sistemáticos (figuras 1 y 2). A partir de los datos AATSR (figura 1) se puede observar una mayor acumulación de incendios detectados en la región noroccidental de la península (Galicia), con algunos puntos aislados en Cataluña y Andalucía. Las falsas alarmas, se observan en los sectores orientales, especialmente en Andalucia y Valencia. En cuanto a las detecciones realizadas a partir de imágenes MODIS (figura 2), se observa un número mucho mayor de zonas detectadas, respecto al AATSR, aunque también aumentan notablemente los errores de comisión. Siguen predominando las zonas detectadas en el interior de Galicia, Sistema Central y puntos aislados de la costa catalana y valenciana, Sierra Morena y sur de Málaga y Cádiz. Las falsas alarmas están bastante concentradas en el Valle del Guadalquivir, lo que hace pensar que se trata de quemas agrícolas. También aparecen otros puntos más dispersos en el interior de Cataluña, Extremadura y centro de las dos Castillas, que pueden también obedecer a este factor, pero resulta más problemático de comprobar.

En cuanto a la capacidad de los datos MODIS o AATSR para inferir patrones geográficos de ocurrencia para todos los incendios, se destaca que los valores $k$ de acuerdo entre teselas observadas y detectadas son generalmente bajos, cercanos al 0.10, lo que indica una tasa de concordancia bastante baja. Sin embargo, MODIS presenta un grado de acuerdo espacial mucho más nítido que el AATSR cuando consideramos los incendios más grandes (>100 has), con valores k superiores al 0.6 para MODIS y en torno al 0.2 para AATSR.

\section{DISCUSIÓN Y CONCLUSIONES}

A partir de este análisis espacio-temporal entre incendios detectados mediante los sensores MODIS y AATSR, para el año 2003, podemos concluir que ambos sensores presentan un elevado error de omisión, con valores superiores al $90 \%$ cuando se consideran todos los incendios. La omisión es menor cuando consideramos únicamente los incendios más grandes. Entre los dos sensores utilizados, MODIS es mucho más sensible al detectar focos activos, debido a que el valor mínimo de omisión se sitúa en torno al 80\% para AATSR y en torno al 40\% para MODIS. En cuanto a los errores de comisión, AATSR es más fiable para eliminar falsas alarmas, al trabajar exclusivamente con imágenes nocturnas. MODIS presenta errores de comisión relativamente altos, especialmente en algunas semanas de verano, en donde pueden producirse confusiones con quemas agrícolas, o bien con suelos muy calientes o superficies especulares. En el primer caso, no podrian propiamente clasificarse como errores de comisión ya que se trataria de incendios activos en realidad, pero no están registrados en las estadisticas oficiales de incendios. Si se consiguiera identificar los incendios relativos a quemas de rastrojos, por ejemplo a partir de un mapa actualizado de la cobertura del suelo, esto permitiria ajustar mucho mejor los errores de comisión.

En el cómputo total del análisis temporal en cuestión, puede haber coincidencias entre detectado y observado dentro de la misma tesela. Sin embargo, es preciso interpretar los resultados con cautela, ya que en cada tesela en la que el sensor haya detectado la presencia de un foco activo, ha podido haber muchos más incendios que no hayan sido detectados. Asimismo, al acumular los incendios ocurridos en determinados periodos de tiempo (análisis anual, estacional y semanal), puede suceder que en una tesela en la que haya habido concordancia en la detección, se estén escondiendo falsas detecciones (errores de comisión).

En resumen, podemos afirmar que la tasa de detección de incendios que realiza el sensor MODIS y el sensor AATSR es bastante discreta, respecto a los detectados con los métodos convencionales (observación de terreno, principalmente). Teniendo en cuenta todos los tamaños de incendio, no parece razonable basarse en datos de estos sensores para realizar una estadistica fiable de áreas afectadas por incendios, al menos en lo que se refiere a los productos de incendios activos.

En cuanto al análisis de los patrones de ocurrencia, se puede observar que los datos derivados del sensor MODIS (figura 2), para incendios grandes y en valores acumulados anuales, ofrecen una representación territorial mucho más ajustada a la incidencia real de los incendios que los AATSR (figura 1). En este sentido se puede concluir que MODIS proporciona un acuerdo razonable con los patrones observados. Por lo que puede considerarse el valor acumulado anual como un buen muestreo de la distribución geográfica de la ocurrencia, lo que lleva a subrayar el interés del sensor MODIS para la realización de estudios sobre los patrones globales de ocurrencia.

\section{REFERENCIAS}

Ahern, F. J., GoldAmmer, J. G., et al., Eds. (2001). "Global and Regional Vegetation Fire Monitoring from Space: Planning a coordinated international effort». The Haghe, The Netherlands, SPB Academic Publishing.

ARIno, O. y Melinotte, J. M. (1998). "The 1993 Africa Fire Map». International Journal of Remote Sensing 19(11): 2019 -2023.

Chuvieco, E., Ed. (1999). "Remote Sensing of Large Wildfires in the European Mediterranean Basin». Berlin, Springer-Verlag: 212

Congalton, R. G. y Mead, R. A. (1983). "A quantitative method to test for consistency and correctness in photointerpretation". Photogrammetric Engineering and Remote Sensing 49: 69-74.

CrackNell, A. P. (1997). "The Advanced Very High Resolution Radiometer (AVHRR)". London, Taylor \&t Francis 
ELVIDGE, C. D. (2001). «DMSP-OLS estimation of tropical forest area impacted by surface fires in Roraima, Brazil: 1995 versus 1998». International Journal of Remote Sensing 22(14): 2661-2673.

GIGLIO, L., DesCloITRES, J., et al. (2003). «An Enhanced Contextual Fire Detection Algorithm for MODIS». Remote Sensing of Environment 87 273-282.

GUENTHER, B., XIONG, X., et al. (2002). "On-orbit performance of the Earth Observing System Moderate Resolution Imaging Spectroradiometer; first year of datan. Remote Sensing of Environment 83(1-2): 16-30.

HUdSON, W. D. y RAMN, C. W. (1987). "Correct formulation of the kappa coefficient of agreement». Photogrammetric Engineering and Remote Sensing 53: 421-422.

JusticE, C. 0., GigliO, L., et al. (2002). "The MODIS fire products». Remote Sensing of Environment 83(1-2): 244-262.
Martín, M. P., Ceccato, P., et al. (1999). "Fire detection and fire growth monitoring using satellite datan. Remote Sensing of Large Wildfires in the European Mediterranean Basin. E. Chuvieco. Berlin, Springer-Verlag: 101-122.

Martínez, S., TournÉ, I., et al. (2000). "Programa FUEGO: Detección y seguimiento de incendios desde el espacion. IX Simposio Latinoamericano de Percepción Remota, Iguazú.

Pereira, J. M. C. y Govaerts, Y. (2001). "Potential Fire Applications from MSG/SEVIRI Observations». Darmstadt, Eumetsat: 41.

Prins, E. M. y Menzel, W. P. (1992). "Geostationary satellite detection of biomass burning in South American. International Journal of Remote Sensing 13: 2783-2799.

SKIDMORE, A. K. (1989). «An expert system classifies eucalypt forest types using Thematic Mapper data and digital terrain model». Photogrammetric Engineering and Remote Sensing 55: 1149-1464. 
Azcárate Luxán, B.; Azcárate Luxán, M.V. y Sánchez Sánchez, J. (directores) (2006): Atlas Histórico y Geográfico Universitario, Madrid, Editorial UNED, 426 páginas, ISBN: 84-362-5262-4.

Coincidiendo con el inicio del curso 2006-2007, y bajo la dirección de los profesores del Departamento de Geografía de la UNED, Blanca Azcárate Luxán, Ma Victoria Azcárate Luxán y José Sánchez Sánchez, salió de la imprenta una obra que, sin duda, agradecerán los estudiantes universitarios -y los no universitarios-, así como los cada vez más abundantes estudiosos interesados en la Geografía y la Historia. Se trata del Atlas Histórico y Geográfico Universitario, publicado por el Vicerrectorado de Medios Impresos y Audiovisuales de la UNED.

Aunque no es la primera publicación de carácter cartográfico de esta universidad, esta obra es, en el campo de la cartografía, la más ambiciosa publicada por la UNED. Por el número de páginas -426-, la temática abordada -Historia y Geografía universales, como se decía antaño, además de un capítulo dedicado al Arte- y el formato del libro $-21 \mathrm{x}$ $30 \mathrm{~cm}$-, este Atlas será por mucho tiempo un auxiliar inseparable en el estudio de las disciplinas humanísticas impartidas por esta Universidad. $Y$ esperemos que con una adecuada difusión y distribución, de las demás. Y si un buen atlas debe ser una obra maestra de la planificación y el diseño, en la que el creador debe determinar lo que va a mostrar e identificar al usuario al que va dirigido el atlas, éste cumple sobradamente con estos requisitos.

El Atlas se estructura en diez grandes capítulos o bloques, desglosados a su vez en varias áreas temáticas, y éstas en una serie de mapas con su correspondiente comentario al pie o costado. Los capítulos que lo integran son: Prehistoria, Historia Antigua, Historia Medieval, Historia Moderna, Historia Contemporánea -hasta 1914 y desde esta última fecha hasta la actualidad-, Historia del Arte, Geografía del Mundo, Geografía de los Continentes y Grandes Espacios Regionales y, para finalizar, Geografía de España. En total 230 mapas históricos más otros 170 de Geografía con sus respectivos comentarios, y varios gráficos, sobre todo en la par- te geográfica. Claro, generoso en cuanto al espacio, preciso, equilibrado y ajustado al título que encabeza cada mapa, este Atlas incorpora, como se viene haciendo desde hace años en obras de similares caracteristicas, numerosos mapas dedicados al mundo no occidental o extraeuropeo en su parte dedicada a la Historia. Y no mediante mapas de pequeño formato insertados en las esquineras de las hojas, a modo de relleno, como si de algo exótico se tratara. China, el Sudeste asiático, India o África, amén de América, cobran personalidad propia, siendo, como han sido y lo son, actores de primer orden en la Historia y Geografía del mundo.

Aunque en la mayoria de los Atlas históricos sigue primando la información de carácter llamémosle político, no por ello se han descuidado en este Atlas otras vertientes del devenir histórico. Numerosos mapas cubren los aspectos culturales, artísticos y económicos de ese devenir. Desde la economía de la Hispania antigua hasta los primeros focos de la revolución industrial del siglo XVIII, pasando, entre otros, por las rutas comerciales transoceánicas del XVI-XVII, la expansión de la Reforma en Europa o la ignominiosa trata de esclavos, numerosos mapas se van intercalando lo largo de los capítulos dedicados a la Historia Universal entre los de carácter más histórico-político. Una saludable novedad ha sido incluir un capítulo dedicado en exclusiva a la Historia del Arte, desde sus orígenes a las vanguardias actuales.

La que pudiéramos considerar segunda mitad de la obra, ésta de carácter netamente geográfico, se abre en el capitulo VIII -Geografía del Mundo- con un amplio abanico de mapas-mundi temáticos que cubren sobradamente los aspectos físicos y humanos de la Geografía universal: de la geología, tectónica y climatología a la demografía y Geografía Humana y Económica. Este capítulo cede su lugar al IX -Geografía de los Continentes y Grandes Espacios Mundiales-, donde la información de carácter mundial del anterior capítulo ahora se desglosa por continentes y áreas geográficas más o menos compactas $u$ homogéneas -los denominados Grandes Espacios Mundiales- que son los que siguen: Europa (excluidos los paises de la Comunidad de Estados Independientes o CEI), los doce estados de la antigua Unión 
Soviética, salvo las tres repúblicas bálticas, ahora integrados en la "fantasmal" Comunidad de Estados Independientes (CEI), Japón y Corea, China y Mongolia, Sur y Sureste de Asia -Indostán, Indochina e Insulindia-, el Próximo y Medio Oriente, América del Norte, América Latina, África y Australasia.

El capítulo X está dedicado a la Geografía de España. Sigue la ya clásica y útil, por más señas, exposición temática que comienza por la Geografía Física y termina en la Económica y Humana. Los autores no han caído en esta especie de fiebre, que ya es epidemia, por referir cuantos fenómenos haya que cartografiar al marco regional o autonómico, olvidando los otros actores de la configuración territorial de nuestro país: las provincias. En efecto, los fenómenos de alcance regional se reseñan en mapas regionales; pero saludo con agrado la reivindicación de la olvidada - por otros denostada- división provincial para plasmar equilibradamente y en su justa relación espacial numerosos fenómenos de la geografía humana: no salen las cuentas de igual manera si reflejamos las diferencias de densidad de población o del Producto Interior Bruto por habitante si lo hacemos por regiones que por provincias, sobre todo teniendo en cuenta que en España varias Comunidades Autónomas -seis de 17, más dos ciudades autónomas- son uniprovinciales.

Muy de agradecer son los comentarios que acompañan los más de 500 mapas de la obra. Y son de agradecer porque, si bien cada mapa incorpora su respectiva y clara leyenda, el lector menos familiarizado con el tema o la época a que se refiere el mapa -si es histórico, por ejemplo-, puede situarse en las justas coordenadas espaciales y temporales merced a estos comentarios. De esta forma, a la plana información que suministra un mapa, se le puede sumar una amplia gama de matices y variables que sólo la información verbal (escrita o hablada) puede proporcionar. Además de sugerir al lector otras vías por las que encontrar más referencias sobre los temas tratados en los distintos mapas, pues en los comentarios abundan las referencias personales de los protagonistas, las cronológicas y las geográficas o territoriales.
Como señalan sus coordinadores en la introducción, se ha aunado en este Atlas el afán didáctico con el rigor científico. Sobre lo primero baste decir que la hechura de los mapas es muy clara y atractiva. El encuadre, ubicación de la leyenda y distribución de la información -sea simbólico-gráfica o verbal- son los adecuados. Su estructura formal es impecable: sobre el mapa-base, que contiene el "armazón" del mapa, es decir, los elementos geográficos indispensables - costas, si las hay, y ríos-, se superpone la parte temática del mapa. El cuidado uso del color -con sus infinitas posibilidades- y la simbología, permiten una lectura del mapa a cualquiera, sea especialista en la materia o no. Y si no lo es, ahí están los comentarios a los que ya se ha hecho referencia más arriba. En fin, que no hay que recurrir a una lupa, como pasa en algunos atlas, para extraer la información de los distintos mapas.

Sobre el aspecto científico de este Atlas Histórico y Geográfico Universitario, su rigor queda más que asegurado toda vez que un profesor de la Facultad de Geografía e Historia de esta Universidad, o un grupo de ellos, especialistas en cada área temática del Atlas, se ha responsabilizado de ella. La Prehistoria ha corrido a cargo de los profesores José Manuel Maíllo y Ma Victoria Cabrera. De la Antigüedad se han responsabilizado Ma Jesús Pérez y Javier Cabrero. Enrique Cantera ha corrido a cargo de la Historia Medieval, mientras que Marina Alonso y Carlos Martínez lo hacian de la Historia Moderna. Por su parte, Julio Gil Pecharromán lo ha sido de la Contemporánea. Los profesores Víctor Nieto, Olivia Nieto y Genoveva Tusell se hicieron cargo del capítulo dedicado a Historia del Arte. Y los tres coordinadores de este Atlas, es decir, Blanca Azcárate, Ma Victoria Azcárate y José Sánchez, han corrido a cargo de todo el apartado geográfico del Atlas.

En resumidas cuentas, bien venido este nuevo atlas al olimpo de los Atlas para uso y disfrute de geógrafos, historiadores $y$, sobre, todo, estudiosos y estudiantes.

JULIO LóPEZ-DAVALILLO LARREA Departamento de Geografía. UNED 